\title{
A INTEGRAÇÃO DO RIO SÃO FRANCISCO, SANEAMENTO, RESÍDUOS SÓLIDOS E ÁGUA: ALGUMAS LINHAS DE ANÁLISE SOBRE O DIREITO ÀS CIDADES SUSTENTÁVEIS
}

\section{THE INTEGRATION PROJECT OF SAN FRANCISCO RIVER, SANITATION, SOLID WASTE AND WATER: SOME LINES ABOUT THE RIGHT TO SUSTAINABLE CITIES}

\author{
Belinda Pereira da Cunha ${ }^{1}$ \\ Jose Irivaldo Alves Oliveira Silva ${ }^{2}$ \\ Talden Queiroz Farias ${ }^{3}$
}

\section{Resumo}

A obra de transposição ou integração de bacias previa uma série de contrapartidas nas cidades no que se refere, por exemplo, ao tratamento de resíduos sólidos e ao saneamento básico, isso, inclusive, existente no Programa de Revitalização do São Francisco (PRSF). Além disso, perguntase: as cidades que serão atendidas pelas águas da transposição, diante de crises hídricas estão preparadas, por exemplo, para o reuso da água, para o tratamento dos esgotos, dentro da perspectiva do Estatuto da Cidade sobre cidades sustentáveis, uma vez que o direito à cidade sustentável é uma das diretrizes da política urbana? Esses municípios que receberão as águas da transposição possuem sua Política Municipal de Recursos Hídricos? O presente artigo pretende abordar os gargalos e as dúvidas presentes na obra de integração do São Francisco em seus eixos norte e leste, analisamos a relação entre esses e o direito à cidade sustentável, consideramos, principalmente, duas dimensões: os resíduos sólidos e o saneamento básico. Quanto à metodologia, foram utilizados dados secundários e a análise da evolução do projeto de integração como base da pesquisa. A partir de uma pesquisa bibliográfica e análise de dados secundários, elaborou-se esse ensaio. Dessa forma, percebeu-se que há um descompasso entre o que se planeja e o que realmente é implementado na gestão pública brasileira, a partir do que foi verificado no Projeto de Integração e no PRSF.

Palavras-chave: Rio São Francisco; Transposição; Direito às Cidades Sustentáveis.

\begin{abstract}
The work of transposing or integrating basins foresaw a series of counterparts in the cities for, for example, the treatment of solid waste and basic sanitation, which is included in the San Francisco Revitalization Program (PRSF). In addition, it is asked: the cities that will be served by

\footnotetext{
${ }^{1}$ Coordenadora do PPGCJ/UFPB. Integra comissão de avaliação QUALIS Livros CAPES para o quadriênio. Colaboradora do PRODEMA - Mestrado e Doutorado em Meio Ambiente e Desenvolvimento. Coordenadora do Grupo de Pesquisa CNPq "Saberes Ambientais - Homenagem a Enrique Leff: Sustentabilidade, Impacto, Gestão e Direitos". Pós-doutorado CAPES Universidade Autônoma do México, Instituto de Investigaciones Sociales, UNAM. E-mail: belindacunha@hotmail.com

2 Doutor em Ciências Sociais. Doutorando em Direito e Desenvolvimento.Mestre em Sociologia e Especialista em Direito Empresarial. Professor efetivo do curso de Gestão Pública da Universidade Federal Semi-árido (CDSA). E-mail: irivaldo.cdsa@gmail.com

3 Professor da graduação e da pós-graduação (mestrado e doutorado) do Centro de Ciências Jurídicas da Universidade Federal da Paraíba, com atuação nas áreas de Direito Ambiental e Urbanístico. Doutor em Recursos Naturais pela Universidade Federal de Campina Grande. Doutor em Direito da Cidade pela Universidade do Estado do Rio de Janeiro, com estágio de doutoramento sanduíche pela Universidade de Paris 1/Pantheón-Sorbonne (CAPES-COFECUB). E-mail: taldenfarias@gmail.com
} de Campina Grande, Ciência Sociais e Educação do Campo, no Centro de Desenvolvimento Sustentável do
\end{abstract}


the transposition waters, in the face of water crises are prepared, for example, for the reuse of water, for the treatment of sewage, within the perspective of the City Statute on sustainable cities, Since the right to a sustainable city is one of the urban policy guidelines? Will these municipalities that will receive the transposition waters have their Municipal Water Resources Policy? The present article intends to analyze the bottlenecks and doubts present in the work of integration of the São Francisco in its north and east axes, analyzing the relation between them and the right to the sustainable city, considering, mainly, two dimensions: solid waste and sanitation basic. As for the methodology, secondary data were used and the analysis of the evolution of the integration project as the basis of the research. From a bibliographic research and analysis of secondary data, this essay was elaborated. In this way, it was noticed that there is a mismatch between what is planned and what is actually implemented in the Brazilian public management, based on what was verified in the Integration Project and the PRSF.

Keywords: San Francisco River; Transposition; Right to the Susteinable Cities.

\section{INTRODUÇÃO}

A região semiárida nordestina, especificamente dos estados de Pernambuco, Paraíba, Rio Grande do Norte e Ceará, está recebendo as águas da transposição do São Francisco, no contexto do Projeto de Integração de Bacias do São Francisco (PISF), sendo esperado por todos a inauguração de um novo momento para cerca de 12 milhões de cidadãos. Esse processo instiga a pensar como as cidades estão preparadas para essa nova realidade de suposta "abundância" de água na região, sempre habituada à escassez hídrica, em menor ou maior proporção.

A obra de transposição ou integração de bacias previa uma série de contrapartidas nas cidades no que se refere, por exemplo, ao tratamento de resíduos sólidos e ao saneamento básico, isso, inclusive, previsto no Programa de Revitalização do São Francisco (PRSF). Além disso, as cidades que serão atendidas pelas águas da transposição, diante de crises hídricas, que já não ocorrem apenas no semiárido, mas tem acontecido no Estado de São Paulo, no Rio Grande do Sul, estão preparadas, por exemplo, para o reuso da água, para o tratamento dos esgotos, dentro da perspectiva do Estatuto da Cidade sobre cidades sustentáveis, uma vez que é uma das diretrizes da política urbana vigente o direito à cidade sustentável? Esses municípios que receberão as águas da transposição possuem sua Política Municipal de Recursos Hídricos?

É importante observar que o PRSF foi uma espécie de contrapartida em relação ao PISF, produto da pressão social e da ação continuada do Ministério Público Federal (MPF) embargando a obra por diversas vezes, sendo um conjunto de projetos de recuperação do rio, sem contar com as ações compensatórias referentes ao PISF. A despeito de toda urgência das 
águas, diante do colapso hídrico de cidades importantes da região como Fortaleza, Campina Grande, Mossoró, Caicó, entre outras, precisa-se problematizar as necessidades frente à sustentabilidade desse recurso, no caso a água, vez que que ele não é infinito. Outra questão que surge é justamente quanto à gestão hídrica, depois que chegar as águas nos seus destinos, reservatórios e canais, como será feito o controle desse recurso? Se for observado outro projeto de transposição ocorrido nos Estados Unidos da América, o Big Thompson, no Estado do Colorado, é feita a gestão mediante medição, transparência das ações, e participação, trata-se de uma região que sofre com a escassez de água, mas com a transposição de rios e do degelo das montanhas rochosas, consegue-se utilizar a água de forma racional nos períodos necessários. Entretanto, ao que parece, o Brasil não é um país de tradição ortodoxa no que tange ao planejamento e consequente investimento na gestão de recursos hídricos, e ao longo dos eixos da transposição o que parece é que há um despreparo da cidades quanto ao saneamento e o tratamento dos resíduos sólidos.

Depois de 10 anos da Lei de Saneamento Básico ${ }^{4}$ completos este ano de 2017, cerca de 50\% da população ainda não tem acesso aos serviços de saneamento básico, e tem-se $17 \%$ da população sem acesso aos serviços de fornecimento de água ${ }^{5}$ (BRASIL, 2017), isso significa mais de 100 milhões de pessoas utilizando meios alternativos para lidar com os dejetos. Depois de 10 anos da sanção do referido diploma legal, a evolução foi de $43 \%$ para $50 \%$ de cobertura em esgotamento sanitário; e de 80\% para 83\% de acesso à água encanada, o parece ser pífio diante da relevância desses serviços e seus reais impactos na vida e saúde das pessoas.

O Quadro 1 demonstra o quão grave é a situação do Brasil quanto ao acesso ao saneamento básico, direito humano previsto desde 2010 em Resolução da ONU (Organização das Nações Unidas) ao lado do direito à água, que precisa avançar de forma mais rápida, uma vez que existe toda uma prioridade no discurso quanto às políticas ambientais de sustentabilidade, o Estatuto das Cidades já preconizava como diretriz de uma política urbana a necessidade de se ter cidades verdadeiramente sustentáveis. Numa observação rápida dos municípios brasileiros (SNIS, 2017), verifica-se a ausência de universalização do saneamento básico, da água, do tratamento de resíduos sólidos, da reciclagem, enfim, podem ser elencados diversos fatores que corroboram com a visão que se atingiu um patamar extremamente mitigado.

\footnotetext{
${ }^{4}$ lei n. 11.445 de 2007

${ }^{5} \mathrm{http}$ //g1.globo.com/economia/noticia/saneamento-melhora-mas-metade-dos-brasileiros-segue-semesgoto-no-pais.ghtml?utm_source=facebook\&utm_medium=share-bar-desktop\&utm_campaign=sharebar
} 
Sendo assim, o presente artigo pretende abordar os gargalos e as dúvidas presentes na obra de integração do São Francisco em seus eixos norte e leste, analisando a relação entre esses e o direito a cidades sustentáveis, considerando, principalmente, duas dimensões: os resíduos sólidos e o saneamento básico, utilizando dados secundários e observações na execução do projeto de integração.

\section{Quadro 1 - Cobertura aos serviços de abastecimento de água e de esgotamento} sanitário nos Estados Brasileiros.

\begin{tabular}{|c|c|c|}
\hline & ÁGUA (\%) & ESGOTO (\%) \\
\hline DF & 99,0 & 84,5 \\
\hline SP & 95,6 & 88,4 \\
\hline PR & 92,8 & 66,55 \\
\hline RJ & 92,2 & 64,5 \\
\hline MT & 87,8 & 25,6 \\
\hline GO & 87,5 & 47,8 \\
\hline RS & 87,2 & 29,4 \\
\hline SC & 86,9 & 19,5 \\
\hline MS & 86,1 & 42,7 \\
\hline SE & 84,3 & 18,4 \\
\hline TO & 83,4 & 22 \\
\hline MG & 82,5 & 69,1 \\
\hline ES & 82,2 & 47,4 \\
\hline RR & 80,0 & 38,1 \\
\hline RN & 79,5 & 22,5 \\
\hline BA & 79,2 & 34,8 \\
\hline PI & 76,5 & 20,9 \\
\hline AL & 76,4 & 20,9 \\
\hline AM & 76,3 & 7,7 \\
\hline PE & 76,1 & 20,8 \\
\hline PB & 75,3 & 34,3 \\
\hline CE & 64,0 & 25,2 \\
\hline MA & 56,2 & 12,1 \\
\hline PA & 47,1 & 4,9 \\
\hline AC & 47,0 & 12,5 \\
\hline RO & 44,2 & 4 \\
\hline AP & 34,0 & 3,8 \\
\hline
\end{tabular}

Fonte: SNIS, Sistema Nacional de Informações do Saneamento, 2017 (BRASIL, 2017)

Há um descompasso entre o que se planeja e o que realmente é implementado na gestão pública brasileira, tendo em vista o resultado apresentado acima, e agora temos a transposição iniciando a sua operação e que no contexto de uma realidade anacrônica desse 
setor de águas e saneamento. Dessa forma, o presente artigo estará organizado, inicialmente, com uma descrição tanto da transposição como da revitalização e uma problematização entre o PISF, o PRSF e fundamentos para uma cidade sustentável a partir da experiência inicial do funcionamento do Eixo Leste e do inconclusivo Eixo Norte.

\section{O MEGAPROJETO DE TRANSPOSIÇÃO DAS ÁGUAS DO SÃO FRANCISCO}

O projeto de transposição do rio São Francisco já fora pensado desde o final do século XIX, em virtude de grandes secas na região do semiárido nordestino. Segundo Andrade (2002), duas tentativas de transposição aconteceram nos períodos de 1982-1985 e 1993-1994, abortadas pela Companhia Hidroelétrica do São Francisco (CHESF) uma vez que haveria a retirada excessiva de água do rio, algo entre 300 e $500 \mathrm{~m}^{3} \cdot \mathrm{s}^{-1}$, sendo um dos empecilhos para a realização dessa obra.

Em 1996, foi formado um grupo de trabalho (ANDRADE, 2002) na Câmara dos Deputados para retomar o processo de estudo acerca da transposição, liderado pelo Deputado Federal paraibano Marcondes Gadelha que, originalmente, propunha a imediata transposição, juntamente com a transferência de águas do rio do Sono, em Tocantins, caso a transposição incluísse também o Piauí, como compensação, bem como estava prevista a venda da CHESF como forma de sustentar financeiramente o empreendimento. À época, a defesa do parlamentar paraibano era no sentido de que o gasto com a transposição se justificaria pelo alto volume de recursos federais gastos para amenizar os efeitos da seca todos os anos (ANDRADE, 2002). Pode-se dizer que uma forte marca desse projeto foi seu "caráter salvacionista".

O projeto foi retomado nos anos 2000 , sendo reiniciado esse processo no âmbito do poder executivo, no governo do presidente Fernando Henrique Cardoso que depois o abandonou, haja visto que proposta da política nacional de recursos hídricos. Como parte dessa institucionalização, foram estruturados órgãos responsáveis pela gestão dessa política, que seguia uma lógica de compartilhamento entre governo e sociedade (LIMA, 2009).

Os opositores ao projeto fundamentam-se principalmente na questão ambiental, na compreensão dos danos e dos conflitos que esse megaprojeto pode trazer sobretudo aos aspectos socio-ambientais, causando prejuízos ao rio e aqueles que necessitam para viver e reproduzir seu modo de vida. Os defensores também incorporaram elementos ambientalizados, ou seja, expressões como desenvolvimento sustentável passaram a fazer parte do projeto pela compensação ambiental e pelo Programa de Revitalização, num nítido processo de 
ambientalização do discurso (LOPES, 2006), na medida em que disseminam a possibilidade de conciliar desenvolvimento econômico e proteção da natureza.

Em junho de 2003, foi constituído um Grupo de Trabalho Interministerial, coordenado pela Vice-Presidência da República, que deu origem ao Plano São Francisco, composto dos programas, projetos e ações: Programa de Revitalização da Bacia do Rio São Francisco (PRSF); Projetos de Integração de Bacias Hidrográficas (PIBH); Projetos de Armazenamento e Distribuição de Águas (PROAD); ações localizadas de infraestrutura hídrica e ações na área de gestão dos recursos hídricos. O processo de revitalização da bacia não estava previsto no projeto original de transposição do rio São Francisco, instituído em 2001 por decreto presidencial. (SILVA e CUNHA, 2014).

A execução do projeto de transposição encontra-se na área do Polígono das Secas, sendo que o Nordeste Setentrional que compreende parte do Semiárido ao norte do rio São Francisco é a área que mais sofre os efeitos de secas prolongadas, abrangendo parcialmente os Estados de Pernambuco, Ceará, Paraíba e Rio Grande do Norte, sendo esse um argumento forte no convencimento acerca da pertinência da obra.

No Relatório de Impacto Ambiental (RIMA) do Estudo de Impacto Ambiental (EIA) de 2004, esse projeto é intitulado "Projeto de Integração do Rio São Francisco com Bacias Hidrográficas do Nordeste Setentrional" e considerado oficialmente como projeto de infraestrutura hídrica. Serão dois sistemas independentes, compostos pelos eixos norte e leste, o eixo leste já se encontra funcionando abaixo do seu potencial, com captação de água no rio São Francisco entre as barragens de Sobradinho e Itaparica, no Estado de Pernambuco. O projeto também prevê canais, estações de bombeamento de água, pequenos reservatórios e usinas hidrelétrica para auto-suprimento. Esses sistemas atenderão às necessidades de abastecimento de municípios do semiárido, do agreste pernambucano e da região metropolitana de Fortaleza, isso foi parcialmente realizado, apresenta-se hoje o canal lesta funcionando com duas bombas das quatro e ainda em processo de acabamento, apesar de ter acontecido duas inaugurações, uma oficial e outra não. Assim descreve o RIMA sobre a finalidade da obra e alguns detalhes técnicos:

Para beneficiar a região mais seca do País, a captação de água do São Francisco será de cerca de 3,5\% da vazão disponível. Em outras palavras, dos $1.850 \mathrm{~m}^{3} / \mathrm{s}$ de água do rio São Francisco, 63,5\% m³/s serão retirados. Desse volume, $42,4 \mathrm{~m}^{3} / \mathrm{s}$ serão destinados às bacias do Jaguaribe, Apodi,, Piranhas-Açu e Paraíba, e 21,1 m³ $/ \mathrm{s}$, ao Estado de Pernambuco, que compartilha a bacia do São Francisco (BRASIL, 2009, p. 2). 
Segundo o discurso oficial, os objetivos do projeto de transposição do Rio São Francisco são os seguintes (BRASIL, 2004, p. 25): "aumentar a oferta de água", "com garantia de atendimento ao semiárido"; "fornecer água de forma complementar para açudes da região", viabilizando a melhor gestão da água; e "reduzir as diferenças regionais causadas pela oferta desigual da água entre bacias e populações". O projeto se compromete a resolver o problema de 12 milhões de pessoas (BRASIL, 2004). O papel do EIA/RIMA, e que foi incorporado pelos agentes públicos do governo, principalmente o executor da obra, Ministério da Integração Nacional (MIN), foi apresentar uma lógica do "benefício que suplanta os danos e conflitos" causados pela obra, ou seja, impactos existem, porém é possível mitigar seus efeitos por meio de soluções que a modernidade oferece, dentro de uma perspectiva salvacionista que vários governos tem utilizado para projetos na região semiárida.

Entretanto, quando se analisa o RIMA isoladamente pode-se incorrer no equívoco de simplificar a abrangência dos efeitos da obra. É preciso ter um olhar mais holístico e, ao mesmo tempo, analítico para perceber que existe uma distância entre o que o governo apresenta como sendo a finalidade dessa intervenção planejada, Projeto de Integração do São Francisco (PISF) e o que verdadeiramente se propõe. Por exemplo, bastando verificar o que está exposto no Plano Estratégico de Desenvolvimento Sustentável do Semiárido (PDSA) (BRASIL, 2005), no Programa de Desenvolvimento Integrado e Sustentável do Semiárido (BRASIL, 2009), no Plano Regional de Desenvolvimento do Nordeste (BRASIL, 2011), chegando-se à conclusão de que o PISF, em conjunto com o PRSF, é uma estratégia de "uso racional dos recursos", inserida numa perspectiva modernizante (GIDDENS, 1991; BECK, 2010), de modo a alimentar a expansão da lógica vigente de desenvolvimento econômico, baseado na expansão dos mercados emergentes, que se utilizam de intervenções planejadas como essa.

Inicialmente, a questão ambiental foi inserida no processo de transposição com graves omissões, segundo Andrade (2002). O consórcio Jaakko Poyry-Tahal foi responsável pelo primeiro estudo governamental acerca dos impactos socioambientais da obra de transposição do São Francisco na década de 1990. Entretanto, a autora acima aponta que a consultoria realizou um estudo incompleto que acabou escondendo os impactos socioambientais da obra, inclusive realizadas em outros países e tomadas como exemplos para o Brasil. Sendo assim, nesse trabalho citado, estão elencadas algumas obras de transposição que tiveram impactos negativos sobre as populações envolvidas e o ambiente natural.

No PISF, além do programa de revitalização, também tem outras ações ambientais previstas em conjunto com as obras, ou seja, 38 programas que fazem parte do Plano Básico 
Ambiental (PBA), um conjunto de medidas mitigadoras dos impactos sociais e ambientais oriundos da execução da obra de transposição. O PBA é formado por 36 Programas Ambientais, contando ainda com mais dois que estão sendo analisados pelo IBAMA, executados no âmbito da obra do PISF, sob supervisão do Ministério da Integração Nacional, que não tem atribuições ambientais. Para subsidiar a etapa de Licença de Instalação, o empreendedor elabora o PBA que detalha as ações necessárias para a minimização dos impactos negativos e maximização dos impactos positivos, identificados quando da elaboração do EIA. O PBA faz parte do processo administrativo de licenciamento das atividades consideradas significativamente poluidoras. Aqui o Instituto Nacional do Meio Ambiente e Recursos Naurais Renováveis (IBAMA) chama de plano que, na verdade, é o Projeto Básico Ambiental mencionado pelo Ministério da Integração Nacional (MIN) (BRASIL, 2004).

\section{REVITALIZAÇÃO COMO LEGITIMADOR DA PROPOSTA DE DESENVOLVIMENTO}

Ao que parece a revitalização assume um sentido de "melhoria das condições de vida" e de "retorno à vida", passando um significado positivo nesse processo de mudança e recuperação. No que se refere à revitalização do rio São Francisco, ela foi uma das dinâmicas de incorporação da questão ambiental no PISF e lembra esses significados adotados no planejamento urbano. Por exemplo, a concepção de revitalização institucionalizada para o PISF, através do PRSF, sob responsabilidade do Ministério do Meio Ambiente (MMA), tem relação com despoluição, conservação de solos, convivência com a seca, reflorestamento e recomposição de matas ciliares, gestão e monitoramento, gestão integrada dos resíduos sólidos, educação ambiental e unidades de conservação e preservação da biodiversidade.

A transposição do rio veio acompanhada de um processo de disputas entre os seus defensores e opositores, os quais encontraram no discurso ambiental um arauto da defesa de seus argumentos, numa postura de "ecologização do projeto estatal". Os defensores da obra fundamentam sua postura na importância da água para a sobrevivência e o desenvolvimento de regiões do Semiárido brasileiro, afirmando que a única possibilidade seria transpor as águas do São Francisco, numa verdadeira conduta salvacionista, corriqueira nessa região, e que é possível conciliar o desenvolvimento trazido pelas águas com a proteção ambiental, adotando instrumentos de desenvolvimento sustentável, desde que se faça a revitalização do rio, mesmo que simultaneamente; e os que são contra, sustentam-se, principalmente, na defesa da existência de sérios riscos ao meio ambiente, causando danos irreparáveis à natureza, sendo 
necessária a revitalização do rio antes de transpô-lo, sendo possível encontrar os mais radicais que são contra a transposição e aqueles que são favoráveis desde que aconteça a revitalização (LOPES, 2004, 2006; SILVA, 2014).

Outros argumentos contrários à transposição dão conta de uma crítica à eficiência da obra quanto ao atendimento de seus objetivos, que acabam tendo relação com argumentações ambientais, não solucionando os efeitos da seca em si, pois trata-se, na verdade, de uma grande obra de infraestrutura hídrica, de alto valor, e que o problema está na gestão das águas (WWF, 2007), que poderia ser resolvido com soluções mais baratas (ANDRADE, 2002; MALVEZZI, 2007), não compensando os prejuízos ambientais causados, uma vez que grande parte da população não teria acesso à água prometida, configurando uma situação de injustiça ambiental (ACSELRAD, MELLO E BEZERRA, 2009), bem como os ecossistemas sofreriam a interferência de espécies não nativas, em virtude dos canais, além da salinização das águas e uso exclusivamente econômico para produção no agronegócio (PAGANO, 2012).

É importante frisar que a revitalização é encarada de forma diferente quando se analisa o discurso de lideranças como Dom Cappio, e o discurso do governo a partir dos seus planos, planejamentos e ações (BRASIL, 2004, 2006, 2009. COELHO et al, 2007). Dom Cappio revela, de um lado, um conjunto de diferenças e conflitos à beira do rio, como a destruição do rio, dos seus peixes e a miséria dos ribeirinhos. De outro, o governo apresenta a solução, da possibilidade de recuperar, recompor, renovar, sem abrir mão de um projeto que trará desenvolvimento econômico e modernidade para a região semiárida nordestina, pois mesmo o eixo leste funcionando isso ainda não se constata, livrando essa região do atraso, através da irrigação, do agronegócio, da navegação, do abastecimento de cidades de médio e grande porte, sendo o abastecimento de água contínuo para o processo de industrialização. (SILVA, 2016).

Portanto, diante disso, seriam duas noções de revitalização, uma "revitalização ecológica", voltada para a recuperação do rio e manutenção de uma dinâmica de subsistência, e outra que seria a "revitalização econômica", sendo um conjunto de ações de renovação do rio, possibilitando um manejo ou uso racional dos recursos. Essa visão oficial do governo deve-se à tônica contraditória da política ambiental brasileira, na qual alguns atores enxergam o meio ambiente como obstáculo ao desenvolvimento, mas buscam incorporar um discurso ambiental modernizador, que tem se aproximado de um modelo de modernização ecológica (SILVA, 2014), na perspectiva de mudanças institucionais necessárias em países industrializados do Ocidente para superar a crise ecológica (SPAARGAREN e MOL, 1995), defendendo uma 
reconfiguração da economia capitalista, de modo a tornar compatível desenvolvimento econômico e proteção ambiental (DRYZEK, 1997).

Outra contradição encontra-se entre a transposição e a revitalização, pois no debate institucional do governo verifica-se a presença muito forte da transposição como responsável pela salvação da população da região dos efeitos da estiagem prolongada, chegando até a quantificar 12 milhões de pessoas (BRASIL, 2004; BRASIL, 2009) como beneficiadas, atestando a transposição como alternativa de desenvolvimento econômico, referindo-se como uma das "apostas" (BRASIL, 2005) para o desenvolvimento da região. A população ribeirinha, por exemplo, defende que o rio está morrendo (ANDRADE, 2002. BATISTA JÚNIOR, 2006), pela falta de peixe e a erosão das margens. Mesmo assim, esse argumento das populações é invisibilizado diante de outros interesses que ressignificam o sentido de natureza (SARMENTO, 2006. GERHARDT et al. 2005).

A transposição não começou tendo uma problemática ambiental como condicionante e não estava baseada numa ampla discussão acerca dos impactos ambientais, mas essa questão transformou-se numa arena política na qual atuaram (e atuam) diversos grupos de pressão da região semiárida, atores sociais diversos (artistas, igreja, associações, ONGs, entre outros) que incorporam a problemática ambiental, que se denomina de uma questão ambiental construída por visões e sentidos (SILVA, 2014). O meio ambiente é inserido posteriormente como elemento muito mais de legitimação do que condicionante dos projetos de transposição e revitalização. Segundo Rocha (2011), o processo de reconhecimento do meio ambiente como questão relevante em si passa pela disputa entre diversas compreensões acerca da sustentabilidade, dentre as quais podemos destacar:

1. A primeira compreensão é de que os problemas relacionados ao meio ambiente são, antes de tudo, ecológicos, sendo assim, a ameaça fundamental consta nos danos aos quais as ações dos homens submetem a terra: patrimônio e base de sua existência presente e futura. Portanto, a sustentabilidade a ser procurada é a ecológica, numa tendência "protecionista" ou "conservacionista", mais ortodoxa ou dura, ou voltada para ecologia profunda, que confere à natureza um valor em si mesma (FERRY, 2009).

2. Um segundo posicionamento não analisa a questão ambiental como isolada da questão social, a sustentabilidade não se coloca apenas em termos ecológicos, mas também sociais, pois justifica-se que não haveria resposta aos problemas ambientais sem tratamento dos problemas sociais; para essa outra tendência a natureza apartada do 
homem não teria valor em si, mas que este valor origina-se da própria existência dos homens e dos usos que dela eles fazem (GERHARDT, 2008).

Em certa medida, pode-se analisar que o projeto de transposição passa por uma compreensão de que a sustentabilidade não pode ser vista apenas pelo prisma da natureza endogênica, ou seja a vegetação e os animais devem ser preservados acima de tudo, mas considerando que o social é condição para que essa proteção ocorra. Nesse modelo, confundese "crescimento" com "desenvolvimento". Entretanto, o projeto de revitalização não se constituía numa prioridade do governo, antes do projeto de transposição das águas do "Velho Chico", como é conhecido localmente o rio São Francisco.

\section{DISPUTAS E CONFLITOS}

Desde de sua elaboração, o projeto divide opiniões. Castro (2011) afirma que há uma polarização entre os estados doadores da água do rio e os receptores da mesma. Um discurso existente aqui, é aquele de que os receptores dessa água só têm a ganhar com o projeto, enquanto os doadores a perder. O que ocorre nesse conflito, afirma o autor, é uma disputa por recursos transferidos pelo governo federal. Vale observar que, foi no decorrer do embate político em torno do projeto, que surgiu uma proposta alternativa a transposição, qual seja, a revitalização do São Francisco. Esta ação passou a ser defendida praticamente como uma espécie de compensação para os estados doadores pela realização do Projeto de Transposição.

Um estudo feito por Castro (2011) sobre o PISF aponta que: a comprovação de déficit hídrico na região receptora é válida somente para bacias beneficiadas nos Estados do Ceará e Rio Grande do Norte; os recursos hídricos da bacia são suficientes para atender a demanda da transposição no médio prazo; os impactos ambientais do empreendimento são grandes e podem piorar; os potenciais benefícios do projeto estão superestimados, a população atendida será menor que a afirmada, e a área irrigada idem e a redução dos gastos emergenciais com as secas não será na proporção prevista; a compensação existente para os estados doadores resume-se ao projeto de revitalização do rio. São problema que se está constatando com o início das operações do canal leste e previsão para Janeiro de 2018 para o canal norte.

Outros estudos desenvolvidos entorno do PISF apontam os seguintes problemas do projeto (OLIVEIRA, 2007; HENKS, 2014; BARACHO, 2014; LIMA, 2013):

a. todo o desenvolvimento do licenciamento ambiental do projeto de transposição violou o que determina a democracia participativa de tomada de decisões; 
b. a obra beneficiará especialmente uma pequena parcela da sociedade;

c. a obra não irá pôr fim a escassez hídrica no Semiárido, mas aumentará a disponibilidade, entretanto, um problema aqui será a democratização do acesso, e não a oferta;

d. os problemas poderiam ser resolvidos com soluções alternativas de menor impacto ambiental e menor custo financeiro e social;

e. o Programa de Revitalização da bacia é melhor aceito pela comunidade local e considerado pela comunidade científica o mais viável e sustentável;

f. o desenvolvimento somente econômico gerado não dará resultados positivos igualitários. Poucos serão amplamente beneficiados com, por exemplo, os pagamentos das desapropriações, das empreiteiras, fazendeiros etc.

g. danos e riscos ambientais atingirão as presentes e futuras gerações;

h. ao longo do percurso de desenvolvimento da obra, várias ações judiciais propostas visando suspender a concessão das licenças ambientais em razão das falhas e omissões relevantes no EIA/RIMA;

i. a obra está sujeita a problemas, consequentes dela mesma, e que podem comprometer sua sustentabilidade e objetivos.

Existe um jogo de forças em torno do projeto, que para a compreensão, faz-se importante analisá-lo a partir de elementos do conceito de campo (BOURDIEU, 2007). As obras de transposição e revitalização do São Francisco configuram-se como verdadeiros campos simbólicos de disputas que agregam diferentes práticas e discursos, vindas de diferentes atores, que ocupam diferentes posições nesse campo, e cujo confronto dar-se-á em torno da utilização dos recursos a elas vinculados e também sobre seus efeitos. Esse processo se enquadra naquele identificado por Silva (2016) em sua obra, em que o meio ambiente assume a forma de campo de disputas. Esses agentes atribuem diferentes sentidos e se relacionam de diferentes formas sobre os processos em questão, tendo em conta as diferentes maneiras como as obras se relacionam com suas condições de existência dentro do espaço em que estão inseridos.

No campo, as relações de poder entre os agentes são assimétricas, sendo que cada dispõe e pode utilizar-se de recursos simbólicos e materiais que variam conforme sua posição. O objetivo maior desses atores é firma-se como dominante, e logo, instituir sua vontade como aquela legitima e aceita. A forma como nesse campo de disputa, o Estado ocupa uma posição privilegiada em termos de fazer valer seus interesses e vontades, expressa relações assimétricas de poder entre eles que repercutem sobre os processos decisórios. Ao que aponta a literatura 
consultada, a tomada de decisões sobre a implementação da obra ocorreu de forma um tanto centralizadora, havendo limites e desrespeitos sobre a participação e deliberações de parcela da sociedade civil. Assim, o Estado, se tratando da implementação do projeto, aproveitando-se de sua posição superior em termos de poder, manipulou elementos do campo a seu favor, em especial aqueles institucionais.

O Estado apresenta um discurso fundado no desenvolvimento sustentável que é para justificar e legitimar a obra, porém, ele não cumpre com esse princípio da sustentabilidade ambiental e do desenvolvimento. Sobre esse discurso do desenvolvimento sustentável, Leff (2001) afirma que ele elude as condições ecológicas que apresentam os limites e contradições da apropriação e transformação capitalista da natureza; esse discurso ignora as diferenças e conflitos entre os atores, apontando para um mesmo propósito entre eles rumo ao alcance do crescimento sustentável. Trata-se de um discurso, em grande medida, cooptado pelo poder e o mercado.

Os objetivos da obra parecem ser mais técnicos, almejando uma gestão racional e eficaz dos recursos. Ela, com seus resultados negativos, viola princípios básicos da sustentabilidade ambiental e do desenvolvimento. Nessas medidas, o discurso que trata dos elementos da sustentabilidade nas ações do projeto, é especialmente performático. Isto é, o faz para legitimar a obra como válida, em especial sob um contexto onde megaprojetos de infraestrutura são alvo de ampla vigilância por parte dos ambientalistas.

O Relatório de Impacto Ambiental (RIMA) do megaprojeto identifica 44 impactos provenientes, sendo 23 considerados como de maior relevância. Desses impactos 12 são positivos e 32 negativos (BRASIL, 2004). A avaliação dos impactos negativos decorrentes, aliada a outras necessidades, levou à elaboração de Programas socioambientais. O sítio do Ministério da Integração Nacional (MIN) na internet lista um total de 38 programas. Um destes é o de Reassentamento de Populações, analisado nessa pesquisa. Três trabalhos de campo foram feitos em Vilas Produtivas Rurais - VPR, ligadas ao programa, nas cidades de São José de Piranhas e Monteiro, na Paraíba, e Sertânia, em Pernambuco. Ainda segundo o sítio do MIN, atualmente existem 382 famílias alocadas em 11 vilas distribuídas entre os estados da Paraíba, Ceará e Pernambuco. A pesquisa teve como resultados (SILVA e OLIVEIRA, 2016):

a. a postura do Estado frente ao processo de deslocamento das populações é de caráter autoritário, desalojando-as de forma danosa em termos financeiros e mediante a ausência de informações precisas sobre o processo em curso e seus desdobramentos para a vida dos afetados; 
b. no caso do desalojamento, o desenvolvimento que representaria a obra mostrou-se de uma inclusão marginalizada - em contraposição a ideia de desenvolvimento includente (SACHS, 2008). Isto porque, o processo não se deu com o devido respeito, preparo e amparo aos atingidos, mostrando-se até mesmo despreocupado com essas questões, vitais a uma inclusão sadia nas Vilas Produtivas Rurais.

c. dentre as atribuições do Estado no processo de autêntico desenvolvimento, algumas são promover parcerias entre os atores que resultem em acordos e planejamento estratégico e gerenciamento cotidiano da economia e sociedade com vistas a um equilíbrio entre diferentes sustentabilidades (SACHS, 2008). A performance do Estado nas vilas fere esses princípios, pois os relatos sugerem uma relação vertical entre 0 governo e os moradores; não se observa nas vilas um conjunto de ações constantes que mobilizem os beneficiários em atividades de qualquer produtividade, ao contrário, vêse o ócio profissional e o pouco contato com os representantes do governos, que nada promovem além de cursos sem muitas implicações práticas se tratando de organização e atividades produtivas - algumas pessoas até relataram descaso sobre eles;

d. Percebe-se entre os beneficiários uma ampla vontade e disposição para a atividade produtiva. Estes, porém, não dispõe dos meios materiais prometidos pelo governo para tal tarefa - as falas relatam cursos de capacitação, acompanhamento técnico, irrigação etc. Ao invés de buscar prover os elementos para a produção, o governo oferece uma quantia mensal, sem que a massiva mão-de-obra disponível seja aproveitada para algum fim. Dessa forma, o governo nega aos beneficiários a capacidade de trabalhar e ampliar sua liberdade, sendo limitada suas capacidades produtivas e criativas que não são exercidas. Esses aspectos, porém, são requisitos básicos para o desenvolvimento pessoal (humano) e o nacional (SEN, 2000);

e. Sendo o desenvolvimento um processo que tem dentre os seus principais objetivos, a oferta de emprego decente e o auto-emprego para toda população, é importante a promoção de ações afirmativas para o melhoramento das condições dos trabalhadores, apoiando formas de atividade empresarial compartilhada. Nesse sentido, é essencial a existência de uma entidade pública que opere como planejador comprometido com os interesses dos pequenos produtores (SACHS, 2008). Ao invés da autonomia financeira de que deveriam dispor os beneficiários, eles têm a completa dependência por meio da oferta de um valor mensal. Ao invés deste auxílio, poderiam contar com um apoio logístico para a produção, dando-Ihes uma rentabilidade que não limite o consumo e as 
oportunidades de aperfeiçoamento e expansão e os frutos do seu trabalho. Nas vilas, não contam com esse suporte, mesmo que o queiram, não havendo assim o governo 0 papel de agente planejador comprometido com os interesses dos trabalhadores locais;

f. Foi observada uma clara falta de iniciativa e vontade política do Estado com relação as vilas, muito embora a ampla gama dos beneficiários sejam produtores rurais que dispõem dos conhecimentos, habilidades e criatividades necessárias a uma organização produtiva dos locais. Não dispondo das ferramentas para tal, só lhes resta esperar a expressão de uma vontade política interessada no desenvolvimento produtivo do local. O desenvolvimento endógeno é tem como condição para tal essa vontade política que desperte as forças criativas (FURTADO, 2002), no caso das vilas, os agricultores;

g. Alguns moradores afirmaram que recebem em cursos prestados pelos representantes do governo alguma instrução sobre práticas de sustentabilidade. Relataram também, uma significativa dificuldade em compreender o conteúdo destes, sendo que alguns afirmaram explicitamente uma complexidade no conteúdo face a capacidade de aprendizagem deles. Nesse ponto é importante ressaltar que a grande maioria dos residentes das vilas possuem baixo nível de escolaridade, havendo ainda um amplo analfabetismo entre os mais velhos. Também, há grande ausência de informações, e até mesmo bastante contradição entre aquelas apresentadas, sobre o conteúdo desses cursos. Isto pode significar uma falta de mediação pedagógica que adapte o conhecimento científico para o conhecimento e cultura dos moradores. O desenvolvimento sustentável requer uma articulação entre os diferentes saberes, em especial o cientifico e o local das comunidades, isto de forma que um contribua para o outro e por fim sejam úteis ao desenvolvimento das comunidades (LEFF, 2002).

h. Há uma ampla desmobilização política dos moradores em se tratando dos processos de organização, decisões e reivindicações. A ação política e iniciativa, ainda tímida, fica restrita especialmente a um pequeno grupo que compõe as associações e a quem é depositada quase toda tarefa de reivindicar, discutir e negociar com os representantes do governo. Esse estranhamento sobre a atividade política coletiva, e, portanto, sobre a vida pública, contrasta com uma dimensão política do desenvolvimento fundada na participação popular sobre as políticas.

\section{O ESTATUTO DA CIDADE E A TRANSPOSIÇÃO DO SÃO FRANCISCO}


O diploma legal conhecido como Estatuto da Cidade, Lei n. 10.257/2001, veio justamente regulamentar os arts. 182 e 183 da Constituição Federal de 1988. Portanto, esses dispositivos versam sobre a política urbana das nossas cidades. De modo geral sua teleologia é justamente estabelecer formas de organizar a vida na cidade. Desse modo, com esse intuito, foi necessário editar o diploma legal supracitado que regulamenta justamente esses dispositivos. Ao que parece um princípio nuclear presente nesses artigos constitucionais é certamente as "funções sociais da cidade", como grifado acima. Isso nos faz remeter justamente para a lei regulamentadora, já citada, em seu art. 2, quando estabelece:

A política urbana tem por objetivo ordenar o pleno desenvolvimento das funções sociais da cidade e da propriedade urbana, mediante as seguintes diretrizes gerais:

$(\ldots)$

XVIII - tratamento prioritário às obras e edificações de infraestrutura de energia, telecomunicações, abastecimento de água e saneamento.

O inciso XVIII, do art. 2, do Estatuto da Cidade foi inserido em 2015, portanto, 14 anos posterior à entrada em vigor dessa lei de organização das cidades no Brasil, considerando, principalmente, que esse inciso acrescentado traz uma preocupação que é contemporânea, premente para os dias atuais: abastecimento de água e saneamento básico. Desse modo, o fornecimento de água e o saneamento são diretrizes para que seja satisfeito o pressuposto principiológico de função social das cidades, o que demorou consideravelmente para ser levado em conta pelo legislador infraconstitucional pátrio.

Entretanto, é importante destacar que o significado de cidade tutelado pela ordem jurídica, partindo do pressuposto que a cidade não é algo individualizado, mas produto coletivo (RODRIGUES, 2004), real, cujas as interrelações se dão intensamente em seu interior e até extrapolando seus limites geográficos. O Estatuto tem como mérito principal chamar atenção à necessidade de planejamento das nossas cidades, considerando que a população urbana é maioria em face da população rural, ou seja, maior parte da população vive nas cidades, e muitas delas num emaranhado caótico que é imposto cotidianamente aos cidadãos, violando frontalmente o direito à cidade e a uma cidade sustentável.

Para se ter uma ideia, a população urbana brasileira, segundo dados do Banco Mundial, dobrou entre 1960 e 2015, perfazendo cerca de 85\% da população brasileira está vivendo em cidades (WORLD BANK, 2017). Dado recente do IBGE dá conta que 68,4\% dos municípios brasileiros tem até 20 mil habitantes, em contraposição a uma concentração de $56 \%$ da população em 5,5\% dos municípios (IBGE, 2016). Portanto, tem-se no Brasil um perfil interessante, poucas cidades concentrando boa parte da população, enquanto a maioria tem 
baixa população, uma concentração urbana considerável, um país essencialmente urbano, daí a importância de se ordenar a vida em cidade.

No semiárido brasileiro, está-se a ponto de se vivenciar uma situação nova de perenização dos reservatórios, fornecimento de água através da transposição das águas do São Francisco, uma promessa de beneficiar 12 milhões de habitantes, principalmente das cidades, com destaque para as de médio porte como Campina Grande, Caruaru, e de grande porte como Fortaleza e Recife. Numa análise acerca da Política Nacional de Recursos Hídricos, é preciso considerar os múltiplos usos da mesma, seja para a dessedentação, seja para a agricultura, seja para a indústria, entre outras. O que é importante observar é pensar nessa água chegando às cidades ao longo dos eixos leste e norte de Pernambuco, Paraíba, Rio Grande do Norte e Ceará, e refletir se as cidades estão preparadas para tal, especificamente no que se refere à gestão dessas águas, isso inclui distribuição, acessibilidade, saneamento, reuso, ações de revitalização. Deve-se frisar que o Programa das Nações Unidas da o Desenvolvimento (PNUD) elaborou os Objetivos do Desenvolvimento Sustentável (ODS) compondo uma agenda 2030 para o desenvolvimento sustentável, quais sejam (ONU, 2015):

\section{(...)}

Objetivo 6. Assegurar a disponibilidade e gestão sustentável da água e saneamento para todos (...)

Objetivo 11. Tornar as cidades e os assentamentos humanos inclusivos, seguros, resilientes e sustentáveis (...)

Destaquem-se os objetivos 6 e11, o primeiro traça a relevância da água e de seu manejo sustentável e do saneamento básico, isso conjuga-se diretamente com o segundo, objetivo 11, que pauta a cidade como sendo importante para o desenvolvimento humano notadamente em relação à premência da sustentabilidade. Portanto, a cidade é o locus privilegiado onde ações concretas de gestão pública, materializadas através de políticas públicas, devem interferir diretamente para o cumprimento da função social desse espaço, e no caso da transposição tem-se um elemento complicador, que acaba sendo ao mesmo tempo a solução para o problema da seca, que é a chegada das águas e a necessidade de um "novo olhar" sobre os recursos hídricos de forma sustentável, sem desperdícios, com destaque para a eficiência do sistema.

Outrossim, em relação à transposição, além das ações de compensação ambiental, tem um grande Programa de Revitalização do São Francisco (PRSF), instituído pelo Decreto de 5 de junho de 2001 da Presidência da República, cujo marco legal estabeleceu alguns eixos, no art. 3, que se relacionam com as funções sociais da cidade, quais sejam: despoluição, conservação de 
solos, convivência com a seca, reflorestamento e recomposição de matas ciliares, gestão e monitoramento, gestão integrada dos resíduos sólidos, educação ambiental e unidades de conservação e preservação da biodiversidade.

Porém, é importante destacar que foi editado um novo decreto n. 8.834 de agosto de 2016, que revogou o decreto supramencionado, o que pode indicar a falta de gestão do programa de revitalização, uma vez que, só agora, no novel decreto, estabelecem-se o Comitê Gestor (CG-PRSF) e a Câmara Técnica (CT-PRSF) da revitalização que, a despeito da importância da transposição, é tão ou mais relevante que a transposição, pois será com esse conjunto de ações e de políticas ambientais que o fornecimento da água poderá ser garantido e ser sustentável (SILVA, 2016). Houve um retrocesso nesse novo decreto em relação ao anterior de 2001, pois o anterior estipulou os eixos de atuação, citados acima, sendo um ponto de partida para execução de políticas pela gestão pública, o que foi revogado, deixando, ao que parece, a responsabilidade de estabelecer as ações da revitalização ao CG-PRSF e ao CT-PRSF, conforme texto da própria peça legal.

Mesmo com essa revogação, considerem-se ainda os eixos acima relatados como plausíveis para uma revitalização necessária desse manancial e relacionados com a gestão das cidades e o cumprimento de suas funções sociais, dentre elas despoluição, conservação de solos, convivência com a seca, reflorestamento e recomposição de matas ciliares, gestão e monitoramento, gestão integrada dos resíduos sólidos, educação ambiental e unidades de conservação e preservação da biodiversidade. Quando observam-se esses eixos e pensa-se nas cidades, especificamente as cidades que estão ao longo dos eixos da transposição, ou que serão beneficiados pelas águas da transposição, verifica-se muitas ações a serem feitas, uma vez que esses municípios não tem uma Política Municipal de Meio Ambiente, não possuem uma Política Municipal de Saneamento e não implantaram a Política de Resíduos Sólidos, especificamente em relação à gestão integrada ou não de resíduos sólidos, e os lixões ainda são uma realidade comum. (SILVA, 2011). Abaixo uma amostra da situação em 2011, devendo-se verificar especialmente o semiárido no mapa abaixo, as esferas pretas significam que ainda não há o aterro sanitário, mas apenas o lixão, em azul tem-se os aterros sanitários.

Mapa 1 - situação da gestão dos resíduos sólidos no Brasil 


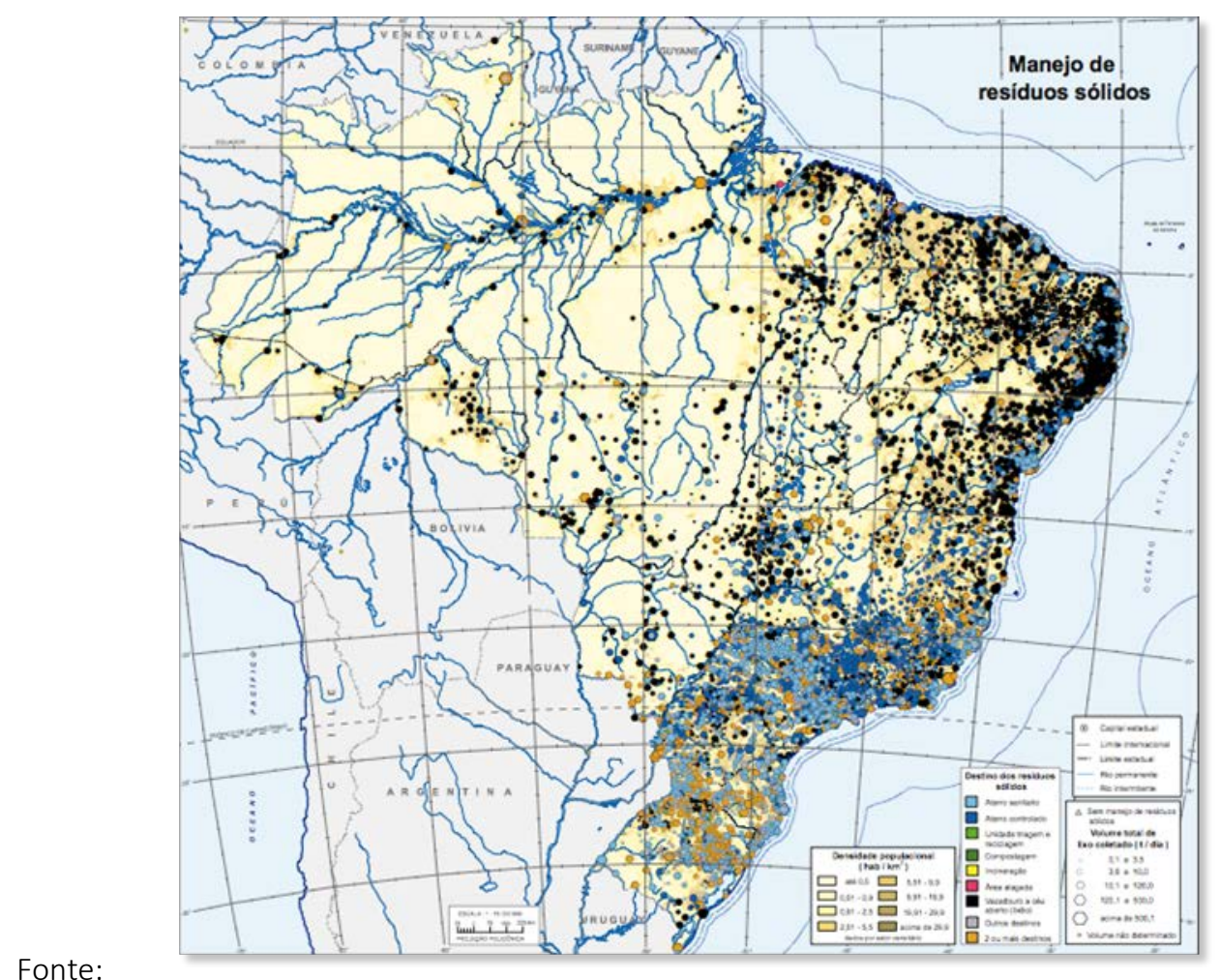

Saneamento, 2011, IBGE.

O Atlas de Saneamento Básico do IBGE foi a última publicação realizada acerca dessa matéria pelo instituto, sendo os dados oficiais mais atualizados, abaixo destacamos os mapas dos estados que serão beneficiados pela transposição.

Mapa 2 - da esquerda para direita e de baixo para cima, Ceará, Rio Grande do Norte, Paraíba e Pernambuco
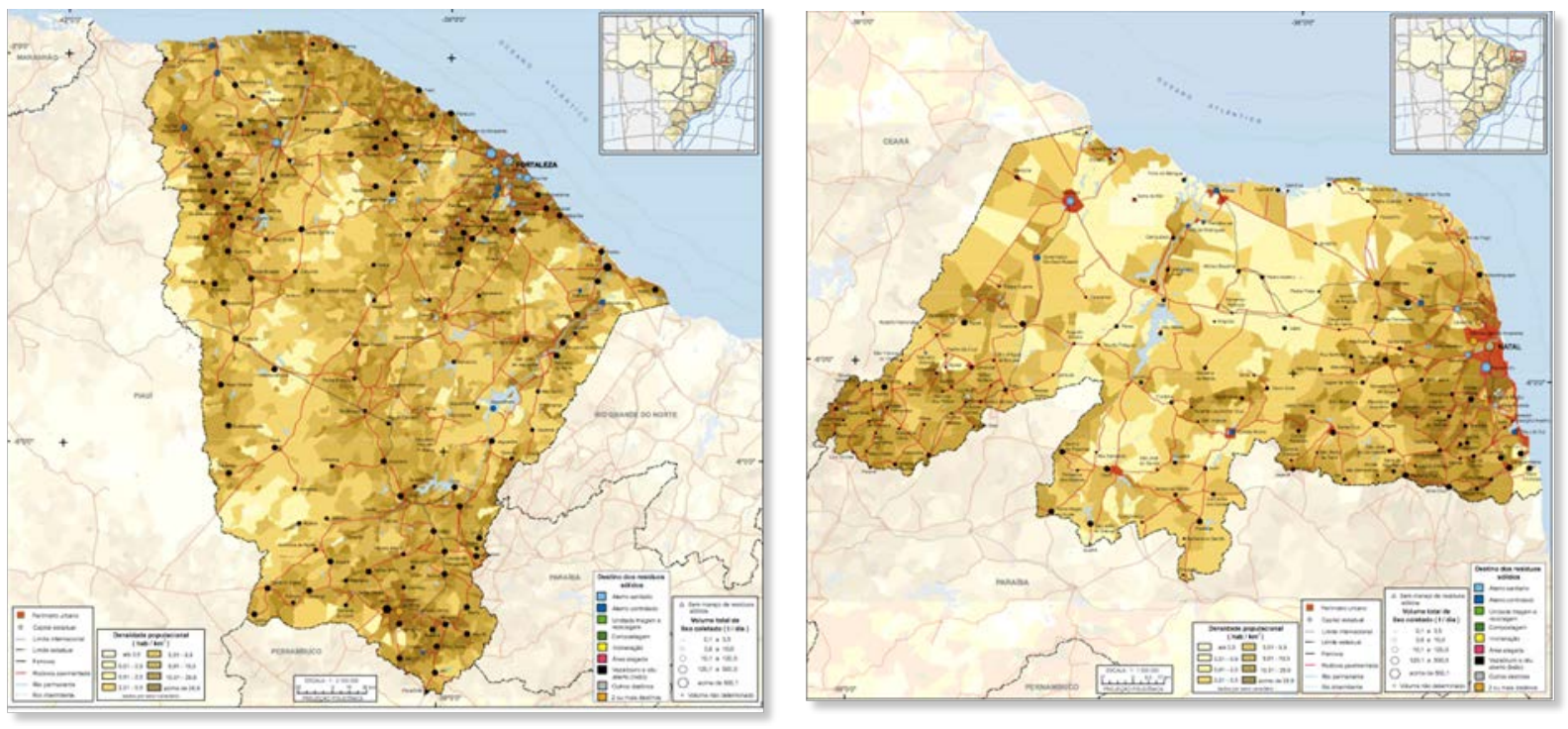

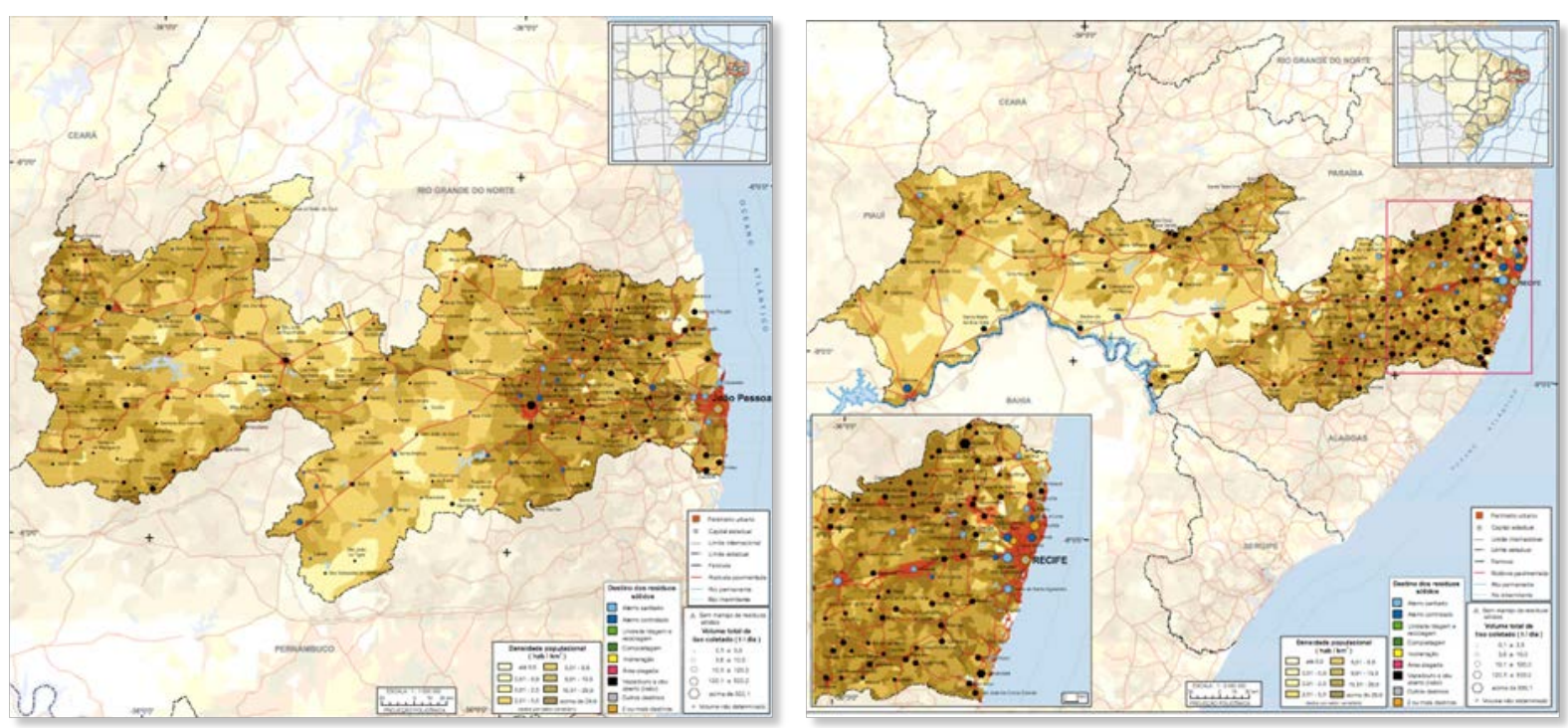

Fonte: Atlas do Saneamento, 2011, IBGE.

Porém, acessando a pesquisa realizada em 2014 pela ABRELPE (Associação Brasileira de Empresas de Limpeza Pública) verifica-se que pouca coisa mudou dessa realidade, ainda o Nordeste é a segunda região que mais produz resíduos sólidos, e a segunda pior em reciclagem (ABRELPE, 2014). Abaixo tem-se alguns dados:

\section{Tabela 1 - Destinação final dos resíduos sólidos no Brasil}

\begin{tabular}{|l|c|c|c|c|c|c|}
\hline \multirow{2}{*}{ Destinação Final } & \multicolumn{7}{|c|}{$2014-$ Regiões e Brasil } \\
\hline Aterro Sanitário & Norte & Nordeste & Centro-Oeste & Sudeste & Sul & BRASIL \\
\hline Aterro Controlado & 93 & 455 & 164 & 820 & 704 & 2.236 \\
\hline Lixão & 112 & 505 & 147 & 644 & 367 & 1.775 \\
\hline BRASIL & 245 & 834 & 156 & 204 & 120 & 1.559 \\
\hline
\end{tabular}

Fonte: Pesquisa ABRELPE

Chama atenção que o Nordeste é a região que mais possui Lixões em atividade, para se ter uma ideia, na região onde chegará um dos eixos da transposição, eixo leste, na Paraíba, nenhum município possui aterro sanitário desde muito tempo como apontam algumas pesquisas (SILVA, 2011, SILVA et al, 2015), bem como não reciclam seus resíduos sólidos, essa é uma realidade totalmente em desacordo com a Política Nacional de Resíduos Sólidos (PNRS), Lei n. 12.305, 2 de agosto de 2010, que prevê em seu artigo 54 que a disposição correta dos 
resíduos sólidos seria feita nos municípios brasileiros em até 4 anos após a entrada em vigor do diploma legal citado, seria um dos legados da copa, o que foi adiado para 2017. Lembre-se que com as Olimpíadas a gestão pública brasileira não conseguiu nem limpar a Baía da Guanabara, um verdadeiro "lixão" da "Cidade Maravilhosa". Em 2015, O Tribunal de Contas da União (TCU) exarou acórdão sobre auditoria realizada referente à gestão do PISF no que se refere ao saneamento básico, abaixo seguem algumas conclusões (BRASIL, 2015, p. 7):

a) em 78 convênios (55\%) as obras estavam paralisadas, em ritmo lento de execução ou não iniciadas com atraso superior a dois anos;

b) em 55 convênios (39\%) os objetos não estavam concluídos, mas os prazos de vigência dos convênios estavam expirados;

c) em 42 convênios (30\%) as licenças ambientais de instalação estavam vencidas;

d) em 18 convênios (13\%) as empresas contratadas para execução das obras tinham capacidade operacional incompatível com a execução das mesmas;

e) em 13 convênios (9\%) foram identificadas movimentações atípicas nas respectivas contas bancárias; e

f) há risco de poluição das águas do Pisf, visto que, em $57 \%$ dos municípios da área de influência direta do projeto, não há serviços adequados de esgotamento sanitário, nem há convênio para execução de obras de esgoto.

Situação grave que demonstra o nível de amadorismo e o descumprimento do Estatuto das Cidades quando às funções sociais, e mesmo que não houvesse a obra de transposição, é vital para a saúde da população a coleta adequada e o tratamento de esgotos. Chama atenção também o mapa elaborado pela equipe do TCU sobre o tratamento de esgotos na área de influência dos canais da transposição.

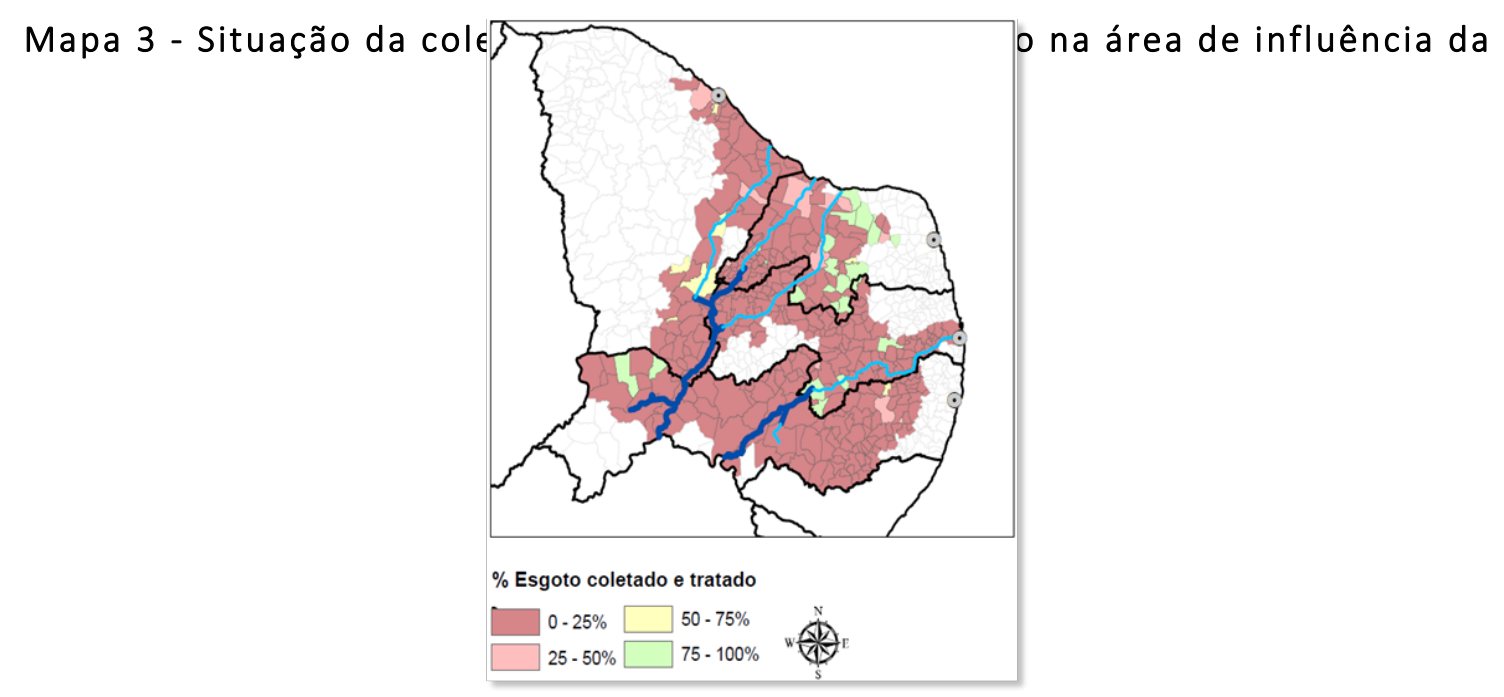

Fonte: TCU, 2015 
O Mapa 3 demonstra cabalmente a situação que se apresente para este momento com a chegada efetiva das águas, sem a devida preparação das cidades que serão beneficiadas pelas águas do "Velho Chico". O Sistema Nacional de Informações sobre Saneamento (SNIS) em relatório lançado este ano (2017) sobre o fornecimento de água, o serviço de esgoto e tratamento do mesmo, verificou-se uma situação que corrobora com essa constatação sobre o pouco avanço em relação ao tratamento dos esgotos, lembrando que apesar de termos uma certa coleta, outra questão fundamental é o tratamento para evitar a poluição que é iminente segundo a constatação do TCU.

\section{Mapa 4 - situação da coleta de esgotos no Brasil}

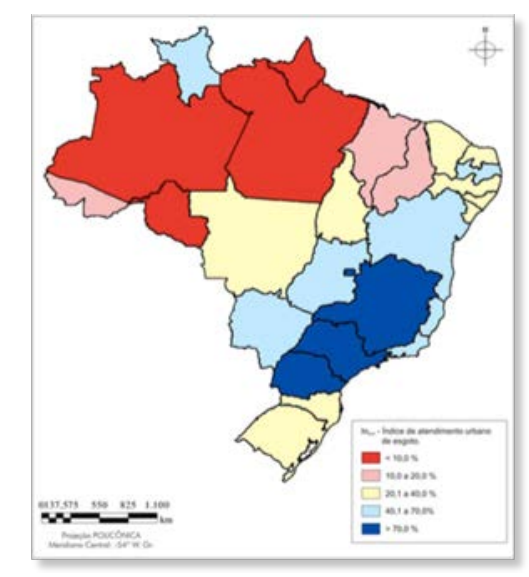

Fonte: SNIS, 2017

O Mapa acima representa a extensão da rede coletora de esgoto, quem está vermelho representa menos de $10 \%$ de cobertura, em rosa fica entre $10 \%$ e $20 \%$ de cobertura, em amarelo entre $20 \%$ e $40 \%$, azul claro entre $40 \%$ e $70 \%$ e azul escuro mais de $70 \%$ de cobertura. Veja-se que, verdadeiramente, é preocupante a situação da área de influência da transposição. O quadro 2 corrobora, reforça a situação de descumprimento das funções sociais das cidades, no momento em que não se priorizou o saneamento básico. 


\section{Quadro 2 - panorama do fornecimento de água, coleta de esgotos}

\begin{tabular}{|c|c|c|c|c|c|c|}
\hline \multirow{4}{*}{ Regiấo } & \multicolumn{4}{|c|}{ Indice de atendimento com rede (\%) } & \multicolumn{2}{|c|}{$\begin{array}{c}\text { Indice de tratamento dos } \\
\text { esgotos (\%) }\end{array}$} \\
\hline & \multicolumn{2}{|c|}{ Água } & \multicolumn{2}{|c|}{ Coleta de esgotos } & $\begin{array}{l}\text { Esgotos } \\
\text { gerodos }\end{array}$ & $\begin{array}{l}\text { Esgotos } \\
\text { coletados }\end{array}$ \\
\hline & Total & Urbano & Total & Urbano & Total & Total \\
\hline & $\left(\mathrm{IN}_{055}\right)$ & $\left(\mathbb{N}_{023}\right)$ & $\left(\mathrm{IN}_{056}\right)$ & $\left(\mathrm{IN}_{024}\right)$ & $\left(\mathrm{IN}_{046}\right)$ & $\left(\mathbb{N}_{016}\right)$ \\
\hline Norte & 56,9 & 69,2 & 8,7 & 11,2 & 16,4 & 83,9 \\
\hline Nordeste & 73,4 & 89,6 & 24,7 & 32,2 & 32,1 & 78,5 \\
\hline Sudeste & 91,2 & 96,1 & 77,2 & 81,9 & 47,4 & 67,8 \\
\hline Sul & 89,4 & 98,1 & 41,0 & 47,5 & 41,4 & 94,3 \\
\hline Centro-Oeste & 89,6 & 97,4 & 49,6 & 54,7 & 50,2 & 92,6 \\
\hline Brasil & 83,3 & 93,1 & 50,3 & 58,0 & 42,7 & 74,0 \\
\hline
\end{tabular}

Fonte: BRASIL, 2017.

O Nordeste, juntamente com o Norte, é a região com os menores índices de tratamento e coleta, preocupante que uma das diretrizes do PRSF, no caso o saneamento básico, não foi cumprido a contento e que a água chega com esse cenário de ações inacabadas. Abaixo algumas fotos da situação hoje do canal do eixo leste da transposição que está funcionando até Sertania, Pernambuco, rumo à Paraíba.

Foto 1 - Da esquerda para direita, a margem do canal da transposição no Eixo Leste, na altura de Sertania, Pernambuco, e várias pequenas fotos da poluição com resíduos ao longo do canal.
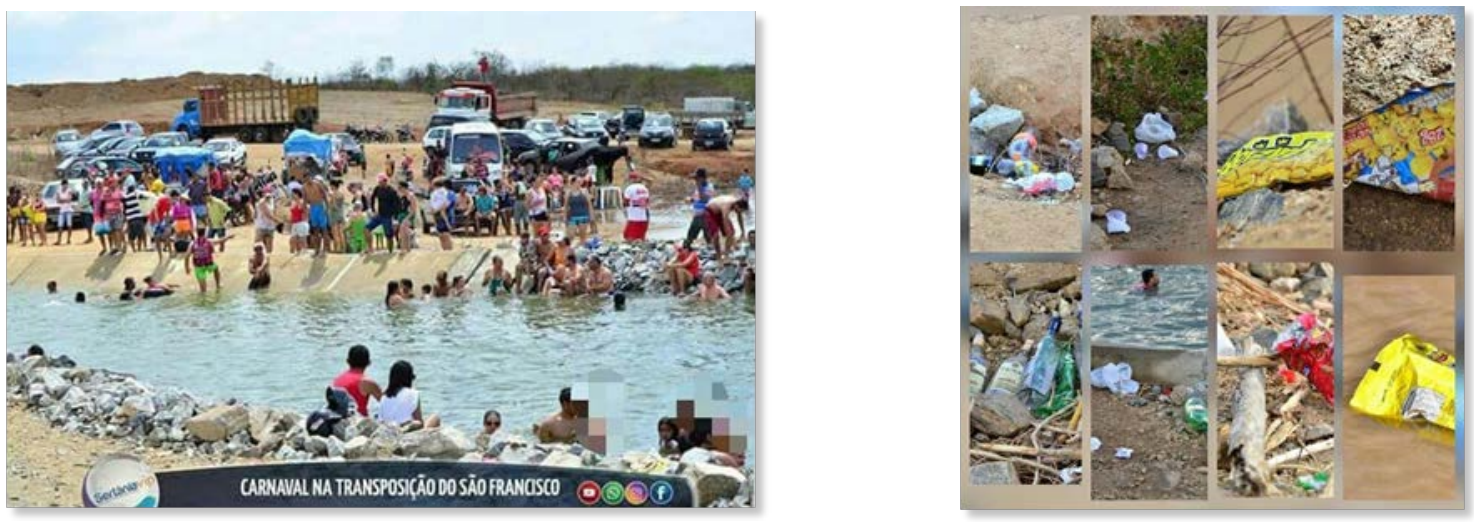

Fonte: Internet

Acima, nas fotos, já se constata o uso indiscriminado da água, o banho em locais inapropriados, sem segurança alguma, e o acúmulo de resíduos que poluem as águas, isso tudo 
conjugado com a falta de tratamento dos esgotos da região de influência do PISF. As cidades não foram preparadas para essa nova realidade, sem saneamento, sem um processo educativo constante, sem fiscalização, sem uma segurança no processo de gestão das águas, que ficará a cargo das companhias de água e esgoto e agência de águas dos estados. Segundo o relatório do TCU (BRASIL, 2015), são 86 municípios que estão inseridos na área de influência direta do PISF, desses $92 \%$ tem coleta e tratamento de esgotos abaixo de $50 \%$. Abaixo tem-se um gráfico que representa o gasto realizado com o PISF e ações do PRSF, com destaque para a ampliação do esgotamento, não significa tratamento desses efluentes.

\section{Gráfico 1 - panorama dos gastos com a Transposição de 2005 a 2013}

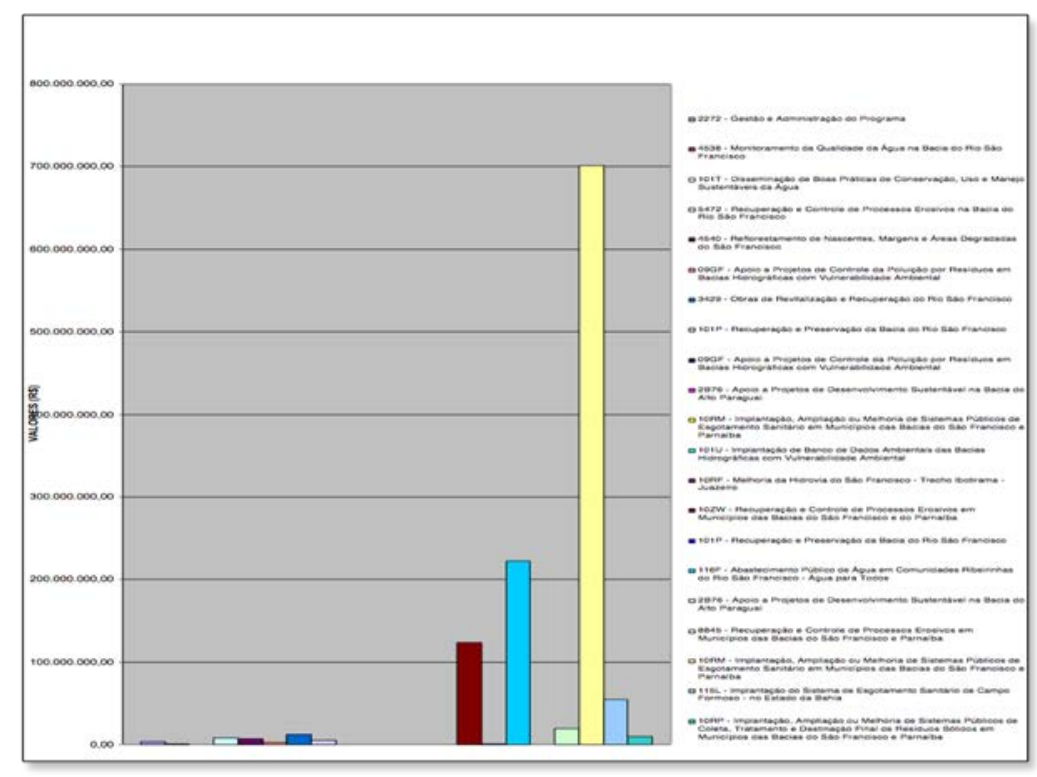

Fonte: SILVA, 2016.

A barra amarela do Gráfico 1 representa o nível de gastos com o esgotamento, porém quando se verifica os dados do TCU e do SNIS tem-se um outro cenário, de obras inacabadas, convênios paralisados, indícios de corrupção, portanto, o que seria um grande avanço com impacto direto na conservação do rio não ocorreu, bem como na prevenção de doenças e, consequentemente, não houve diminuição dos gastos com saúde. No último dia 15 de fevereiro de 2017 houve um seminário de gestão estratégica das águas na Paraíba, organizado pela Federação dos Indústrias da Paraíba - FIEP, para tratar com todos os estados e atores envolvidos na transposição o que fazer depois da chega das águas, principalmente em relação às cidades. Nos dois dias de evento pode-se perceber os seguintes gargalos quanto à gestão dessas águas em relação, por exemplo, ao Estado da Paraíba: 
1. Ausência de gestão de resíduos sólidos;

2. Falta de servidores especializados na agência das águas da Paraíba (AESA);

3. Poluição das águas;

4. Falta de tratamento das águas;

5. Falta de fiscalização dos canais;

6. Educação ambiental deficitária;

7. Furto de água;

8. Os comitês de bacia não estão preparados e não participam efetivamente da gestão das águas e estão desinformados sobre como vai ser com a chegada das águas;

9. A agricultura não está preparada, nem se tem conhecimento como vai ser no plano da irrigação das terras.

Veja-se que o cenário não é em nada auspicioso em relação à gestão das águas. Essa megaobra de infraestrutura hídrica em vários trechos tem suas águas lançadas em leitos de rios, no caso do Estado da Paraíba, o eixo leste, o primeiro em funcionamento, não foi revitalizado, e em diversos pontos o esgoto é jogado nesse manancial sem nenhum tipo de tratamento. Abaixo uma foto do canal na cidade de Monteiro, eixo leste, próximo a um esgoto.
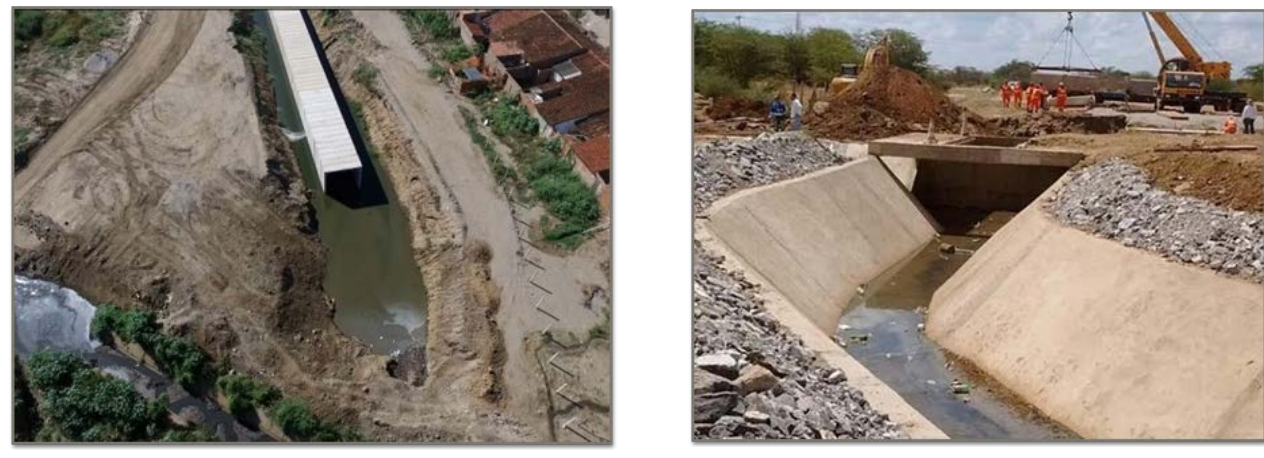

Foto 2 - canal na cidade de Monteiro próximo a um esgoto da cidade.

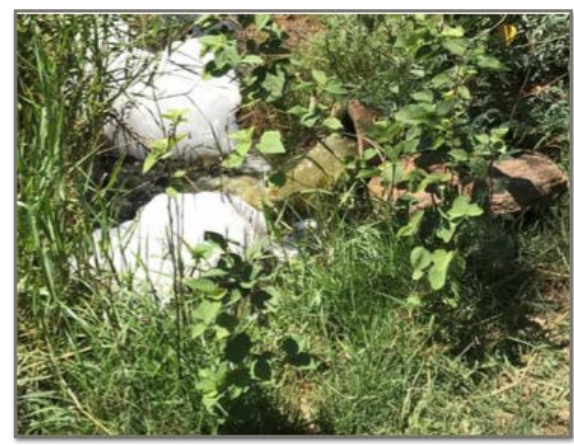

Fonte:http://g1.globo.com/pb/paraiba/noticia/2017/02/mpf-identifica-esgoto-em-canal-da-transposicaodo-sao-francisco-na-pb.html - www.mpf.mp.br/pb/sala-de-imprensa/docs/02-it-03-2017-transposicao-

1 .../file 
Laudo de engenheiro civil em procedimento aberto este ano sobre o andamento da obra de transposição no eixo leste, dá conta sobre a insuficiência de serviços no que se refere à revitalização do rio Paraíba, por exemplo, está assoreado e suas margens estão desprotegidas, sem vegetação, e será por lá que a água irá passar para a cidade de Campina Grande, na Paraíba, que sofre um severo racionamento (MPF, 2007). A imprensa publiciza o não cumprimento de ações necessárias e essenciais para a chegada das águas.

\section{Foto 3 - imprensa local denuncia a situação de descumprimento de ações da transposição}
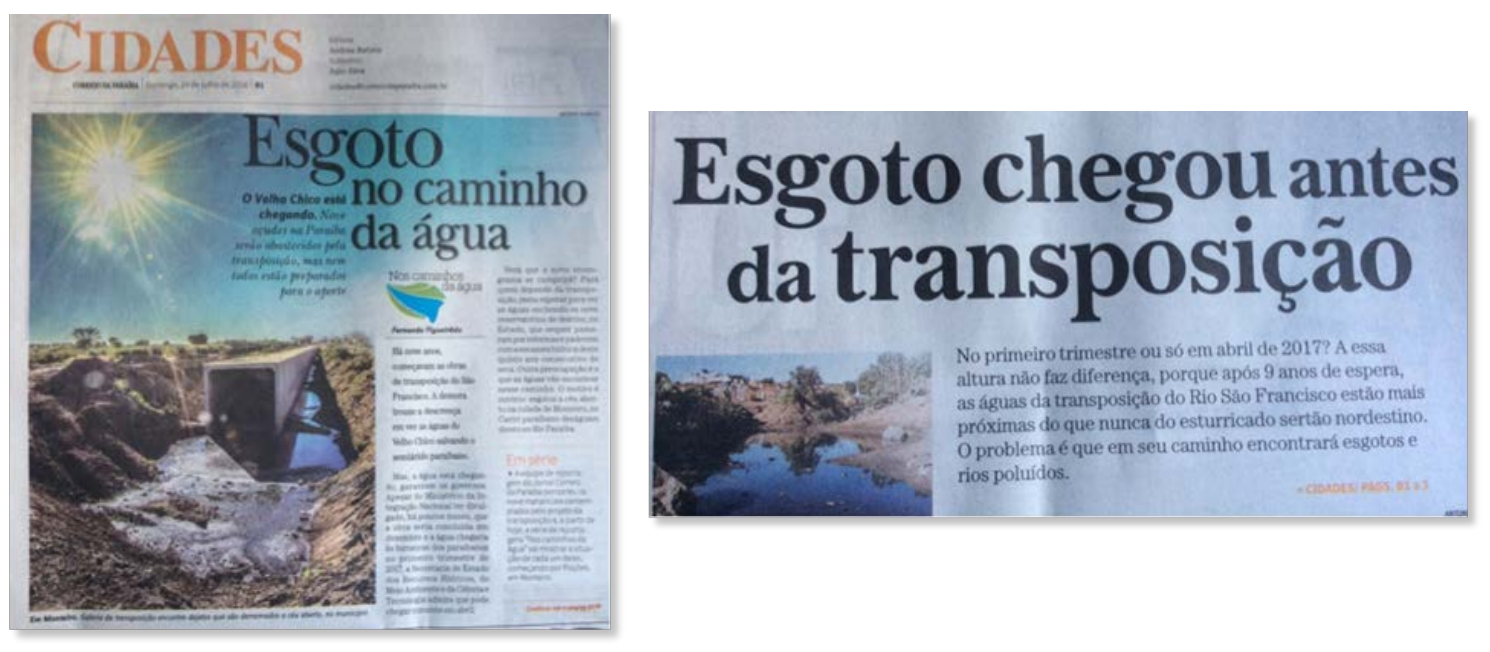

Fonte: Jornal Correio da Paraíba, 2016

O relatório do SNIS (BRASIL, 2017) demonstra que há um descumprimento flagrante dos pressupostos das regras de saneamento básico no Brasil, conforme estabelecido na Lei $\mathrm{n}$. $11.445 / 2007^{6}$, principalmente no que menciona o artigo segundo como princípios fundamentais, quais sejam: universalidade, disponibilidade, esgotamento, tratamento dos esgotos, articulação com as políticas de desenvolvimento urbano e regional, de habitação, de combate à pobreza e de sua erradicação, de proteção ambiental, de promoção da saúde e outras de relevante interesse social voltadas para a melhoria da qualidade de vida, para as quais o saneamento básico seja fator determinante; eficiência, segurança, qualidade, regularidade e controle social ${ }^{7}$.

\footnotetext{
${ }^{6}$ Lei de Diretrizes Nacionais do Saneamento Básico.

7 Não se tem notícias sobre a participação da população nos processos de decisão da política de saneamento, seja estadual, seja municipal, bem como não há um sistema de transparência quanto a essas ações.
} 
O Plano Nacional de Saneamento Básico (PLANSAB), coordenado pelo Ministério das Cidades, previsto no artigo 52 do diploma legal supracitado, finalizado em 2013 deslocou o alcance de metas para 2033, na verdade assumindo a incapacidade do Estado brasileiro em atingir metas básicas como a universalização do fornecimento de água, coleta e tratamento de esgotos (BRASIL, 2013). Daí a preocupação quanto à gestão das águas da transposição e como se darão as ações de conservação das águas dos canais e mananciais receptores. O cumprimento dos princípios previstos da Lei de Diretrizes do Saneamento Nacional é aspecto sine qua non para uma vida saudável e sustentável nas cidades. Interessante verificar que nesse PLANSAB não há um detalhamento num aspecto muito relevante para os dias atuais que é o reuso da água, apenas afirma que será feito o reuso controlado da água, porém, os fatos demonstram que não se avançou na etapa mais primária, o que dizer de uma etapa mais a frente.

Castro (2013) aponta a gravidade da situação, a sua complexidade no mundo inteiro, especialmente em países ainda pobres como o Brasil, e continentes como o africano, pois as metas estabelecidas pela ONU de reduzir o déficit de acesso à água e esgotamento sanitário pela metade até 2015 não foram atingidas, e a principal causa, segundo o estudioso, são fatores relacionados com a gestão pública, tais como componente políticos, institucionais e financeiros. Segundo Castro (2013, p. 57):

(...) o relatório final do grupo de trabalho que monitorou o ODM entre 2000 e 2005 destacou alguns problemas, tais como descompromisso político, a fragilidade das estruturas institucionais, a lentidão das reformas, a manipulação e clientelismo políticos e as restrições financeiras, particularmente nos países mais pobres, onde os governos não dispõem de recursos para investir e os serviços são economicamente inviáveis para grandes parcelas da população (...)

Entretanto, ao longo do século XX os países desenvolvidos passaram nortear suas ações a partir de alguns princípios básicos e fundamentais para reger a política de água e saneamento, quais sejam:

1. papel central do Estado na defesa dos interesses públicos;

2. a especificação e detalhamento do que significam serviços essenciais, inserindo o saneamento na rubrica de bens públicos, exigindo-se sua retirada da esfera do mercando, com a finalidade de atingir um resultado socialmente eficaz;

3. princípio da cidadania social, pelo qual o acesso a bens e serviços considerados essenciais com a água e o saneamento, inclui-se na categoria de bens sociais que deveriam estar ao alcance de todos, fosse qual fosse o seu status no mercado; 
4. papel central do Estado na organização e prestação desses serviços essenciais, a fim de atingir a universalização tão almejada (CASTRO, 2013).

É interessante constatar que numa cidade sustentável capaz, dar aos seus cidadãos pleno acesso à água e ao saneamento básico é condição fundamental proteger o caráter público da água e do sistema de saneamento, na visão de Swyngedouw (2013) não se pode encarar esses dois setores como provedores de mercadoria, e que a tentativa de conferir qualidade ao fornecimento de água e esgoto pela iniciativa privada fracassou (PUBLIC SERVICES INTERNATIONAL RESEARCH UNIT, 2015), em boa parte do mundo, considerando que cerca de 1 bilhão de habitantes urbanos não tem acesso à água potável, e mais de 1 bilhão de moradores não tem acesso ao esgoto, e que no período de 1990 e 2005, anos áureos das privatizações desses setores, apenas 600 mil domicílios receberam novas tubulações nas cidades, caindo para 250 mil se for descontado os subsídios e investimentos públicos. (CASTRO et al, 2013).

O que é mais grave é que o Brasil, como se viu em dados e informações nesse ensaio, pouco avançou no processo de avaliação de sua política pública de saneamento (BERNARDES et al, 2013) e vem cometendo velhos equívocos como esse da transposição, a construção de um canal vertendo água por cidades que ainda não possuem uma estrutura de esgotamento sanitário, reuso de água e de tratamento de resíduos sólidos. E aí, os gestores brasileiros invertem a forma de planejar, parece que esquecendo-se da complexidade de gerenciar recursos de uso comum (JACOBI, 2013), que é o caso da água, em torno de diversos atores que tem interesses diversos acerca do uso de um mesmo recurso.

E, já presenciando, a chegada das águas no eixo leste, já se percebem essas dificuldades de interação, a não preparação prévia das pessoas, das instituições, dos coletivos para lidarem com uma realidade de segurança hídrica, uma realidade nova para o semiárido. Alguns pensam apenas na água de beber, outros na industrialização, outros na agricultura familiar, outros no agronegócio. Para se ter uma ideia, os Comitês de Bacias Hidrográficas da Paraíba não estão preparados, tão pouco discutindo ou sendo orientados quanto a essa nova realidade, indo de encontro a sua funcionalidade que é a redução de riscos de que o "aparato público seja apropriado por interesses imediatistas e amplia as possibilidades de uma prática orientada pela negociação sociotécnica" (JACOBI, 2013, p. 547).

É importante observar que a transposição está submetida ao Estatuto das Cidades como à Política Nacional dos Recursos Hídricos (PNRH), Lei n. 9.433 de 1997, e especialmente em relação a essa última é relevante verificar que o art. 2 estabelece os objetivos dessa política e dentre esses está o seguinte: "II - a utilização racional e integrada dos recursos hídricos, 
incluindo o transporte aquaviário, com vistas ao desenvolvimento sustentável"; e pelo que está ocorrendo na inauguração do eixo leste existem muitos gargalos ainda a serem resolvidos com o eixo leste em pleno funcionamento, modelo de gestão tipicamente brasileiro, que fechou os olhos para os problemas enfrentados pelas diversas transposições que existem no mundo (SILVA, 2016). No caso da Paraíba, para se ter uma ideia inicial, a Agência Executiva de Gestão da Águas (AESA) é a responsável pela gestão da água na transposição desse estado, sendo uma realidade inteiramente nova e estando ainda muito "nebulosa" a capacidade técnica desse órgão estadual, que acaba sendo uma realidade da regulação dos serviços públicos nacionais.

Além da PNRH e do Estatuto das Cidades, ao PRSF aplica-se também os fundamentos e regras da Política Nacional do Meio Ambiente (PNMA - Lei n. 6.938/1981) e o PLANSAB, veja-se que a obra de transposição vai ser finalizada, o eixo leste já inaugurado, e o eixo norte com prazo de inauguração para Janeiro de 2018, entretanto, o PRSF demonstra sua complexidade não só porque não termina com a integração, ela continua com a complexidade na aplicabilidade de diversas normativas legais relacionadas com água, resíduos sólidos, meio ambiente e saneamento básico, questões que repercutem diretamente na vida e saúde da sociedade, envolvendo diversos níveis da gestão pública, atores, sejam estatais ou da sociedade (MACHADO, 2013; TCU, 2012).

Para ilustrar, é relevante resgatar o termo de compromisso firmado entre União, por intermédio dos Ministérios da Integração Nacional (MIN), de Minas e Energia, do Meio Ambiente e da Casa Civil da Presidência da República, e os Estados do Ceará, Paraíba, Pernambuco e Rio Grande do Norte, para garantir a operação sustentável do PISF, em 2005, e que se deve destacar, agora, com a chegada das águas no eixo leste, são as responsabilidades dos estados, quais sejam:

1. Capacitar-se administrativamente, financeira e operacionalmente para gerenciar os recursos hídricos nos seus respectivos territórios, em especial no que se relacionar com os açudes públicos e demais infra-estruturas hídricas interligadas ao PISF, estruturando órgãos e entidades destinados à gestão da água bruta, na forma da Lei n. 9.433/1997 e das respectivas leis estaduais de gestão de recursos hídricos;

2. estruturar órgãos de gerenciamento de recursos hídricos já existentes - a Companhia de Gestão de Recursos Hídricos do Ceará (COGERH), o Instituto de Gestão das Águas do Rio Grande do Norte (IAGARN), a Agência Executiva de Gestão das Águas da Paraíba (AESA) - e criar e estruturar organismo similar, em Pernambuco, conferindo-lhes, preferencialmente, a natureza de sociedade de economia mista visando ao 
desempenho da função de Entidades Operadora Estadual da infra-estrutura hídrica interligada ao PISF, responsável por receber, gerenciar e distribuir, de forma eficiente, a água a ser aduzida pelo PISF;

3. realizar de forma integrada e com articulação da ANA, campanha de regularização dos usos da água na área de influencia do PISF, mediante o cadastramento dos usuários e a implantação da outorga pelo uso da água;

4. implantar a cobrança de tarifas dos serviços de operação, manutenção e de cobrança de direito de uso da água no âmbito do Estado;

5. responsabilizar-se, inclusive financeiramente, pela operação e manutenção dos açudes relacionados no item $\mathrm{I}, \mathrm{a}, 4$;

6. pagar à Entidade Operadora Federal do PISF os custos operacionais e de manutenção a ele relativos, com a implementação de cobrança dos serviços aos usuários finais;

7. acordar garantias financeiras com a Entidade Operadora Federal encaminhando proposta de lei ou decreto, conforme o caso, incluindo entre outras a securitização, através da cessão de direitos da parcela de água bruta destacada na conta de água tratada dos usuários finais dos sistema de saneamento;

8. priorizar investimentos, em parceria com a União, para a implementação de infraestrutura hídrica estadual interligada ao PISF.

São itens importante a serem analisados num futuro breve em outras pesquisas.

\section{CONSIDERAÇÕES FINAIS}

A responsabilidade da gestão é relevante, especialmente dos estados, pelo acordo que foi firmado, ao chegar as águas caberá aos estados o seu gerenciamento, e outras ações que não foram realizadas pelos municípios, como a gestão dos resíduos sólidos. Porém, é bem verdade que as cidades que estão na zona de influência dessa obra ainda não estão adequadas, falta gestão dos resíduos sólidos, saneamento básico e planejamento para o reuso das águas residuais de esgotos residenciais, industriais e comerciais, ainda muito distante para serem concretizadas verdadeiras cidades sustentáveis.

O que se vê na região é a felicidade imediatista pela chegada das águas, pouco se discutindo acerca das obras necessárias para a revitalização do São Francisco, tais como o saneamento básico, os resíduos sólidos e a proteção das águas contra o possível furto de água. É verdade que a necessidade de água suplanta as demais necessidades, é uma prioridade, mas o 
modelo de planejamento urbano que existe no Brasil não abre espaço para discutir os dilemas das cidades de pequeno e médio porte, ainda tem-se políticas inacabadas, que não saem do papel em todo país, como a de resíduos sólidos ou o Plano Nacional de Saneamento Básico, daí pode-se ser alvo potencial de doenças tipicamente de países ainda pobres como o "zika" e a "dengue".

O que se vê é uma grande obra que se ressente de outras obras complementares no campo ambiental, tanto aquelas que dizem respeito à revitalização do rio São Francisco, que tem ações sendo realizadas pelo Ministério do Meio Ambiente (MMA) e pela Companhia de Desenvolvimento do Vale do São Francisco (CODEVASF), bem como, aí, ainda muito a desejar, obras e ações que possam proteger as águas que estão correndo e correrão pelos canais. Causa lamento quando se vê o governo institucionalizando em 2016 o comitê gestor da revitalização, depois de muitos anos de obra, como se a mesma fosse dispensável.

Porém, os estados que receberão necessitarão como nunca reativar ou promover reuniões e ações práticas dos comitês de bacia, sendo fundamental o monitoramento e a busca pelo uso racional da água em suas mais diversas utilidades, é preciso vigilância e cumprimento de regras para se poder usar todo o potencial disponível desse manancial, de forma justa e que atenda aos princípios da PNRH, do Estatuto da Cidade e da Política Nacional do Meio Ambiente, com a real noção que a água ela é escassa e se não for usada de modo racional poderá ser restrita novamente em racionamentos e até mesmo ausência total desse precioso líquido. 0 Eixo Leste que está começando a funcionar já vem demonstrando o nível de problemas que teremos, sem coleta seletiva, sem reuso de água, despejo de resíduos ao longo do canal, desperdício de água, entre outras questões.

Outro aspecto, finalmente, a ser considerado é a necessidade de reeducação das famílias, comerciantes e industriais em relação aos múltiplos usos da água, pois a abundância de água não pode levar a pensar que se deve adotar um comportamento desregrado, mas que agora, mais do que nunca, necessita-se de mudança de hábitos.

\section{REFERÊNCIAS}

ACSELRAD, H. MELLO, C. C. do A. e BeZERRA, G. das N.O que é Justiça Ambiental. Rio de Janeiro, Garamond, 2009.

ANDRADE, R. "Da transposição do rio São Francisco à revitalização da bacia: as várias visões de um rio", http://www.fundaj.gov.br/docs/tropico/desat/renata_andrade.pdf, acesso em 10/01/2013, às 23h, 2002. 
Associação Brasileira de Empresas de Limpeza Pública e Resíduos Especiais (ABRELPE). Panorama dos resíduos sólidos no Brasil. São Paulo: ABRELPE, 2014

BARACHO, L. M. S. Feridas da transposição do São Francisco: um olhar sobre comunidades quilombolas do Semiárido Pernambucano. 2014. 231 f. Dissertação (Mestrado Acadêmico em Saúde pública) - Centro de Pesquisas Aggeu Magalhães, Fundação Oswaldo Cruz, Recife.

BECK, Ulrich. Sociedade de risco: rumo a uma outra modernidade. São Paulo: editora 34, 2010.

BOURDIEU, P. Razões Práticas: sobre a teoria da ação. 8. ed. Campinas: Papirus, 2007.

BRASIL. Ministério do Meio Ambiente. Ações de revitalização na bacia do rio São Francisco. Brasília: MMA, 2009.

Ministério da Integração Nacional. Projeto de integração do Rio São Francisco com Bacias Hidrográficas do Nordeste Setentrional. Relatório de Impacto Ambiental - RIMA. Disponível em: http://www.integracao.gov.br/saofrancisco/integracao/rima.asp. Acesso em 23/07/2011, às 11:30, 2004.

Parecer técnico do IBAMA. Análise do EIA/RIMA do Projeto de Integração do Rio São Francisco com Bacias Hidrográficas do Nordeste Setentrional. Brasília, 2005.

Ministério da Integração Nacional. Plano Regional de Desenvolvimento do Nordeste. Recife, 2011.

Ministérios de Meio Ambiente. Programa de Revitalização da Bacia do São Francisco, disponível em http://www.mma.gov.br/estruturas/PRSF/_arquivos/diag.pdf, acesso em 02/12/2012, 2012.

Decreto no 3.833, de 5 de junho de 2001. Brasília: Presidência da República, 2001.

Lei n. 10.257, 10 de julho de 2001. Brasília: Senado Federal, 2001.

Decreto no 3,833, de 5 de junho de 2001. Brasília: Presidência da República, 2001.

Decreto n. 8.834, de agosto de 2016. Brasília: Presidência da República, 2016.

Atlas do saneamento 2011. Rio de Janeiro: IBGE, 2011.

Tribunal de Contas da União. Relatório de Acompanhamento, TC 010.945/2014-8, Sessão

em 10/6/2015, Ata $n^{\circ}$ 21/2015, plenário, disponível em:

www.tcu.gov.br/Consultas/Juris/Docs/judoc/Acord/.../AC 14212115 P.doc, acesso em 20.02.2017.

Ministério das Cidades. Secretaria Nacional de Saneamento Ambiental - SNSA. Sistema Nacional de Informações sobre Saneamento: Diagnóstico dos Serviços de Água e Esgotos - 2015. Brasília: SNSA/ MCIDADES, 2017.

Plano Nacional de Saneamento Básico. Brasília: Ministério das Cidades, 2013.

Lei n. 9.433 de 8 de janeiro de 1997. Brasília: Senado Federal, 1997.

Lei n. 11.445 de 5 de janeiro de 2007. Brasília: Senado Federal, 2007.

Tribunal de Contas da União. Programa de revitalização da Bacia Hidrográfica do Rio São Francisco / Tribunal de Contas da União; Relator, Ministro Aroldo Cedraz - Brasília: TCU, Secretaria de Fiscalização e Avaliação de Programas de Governo, 2012.

Ministério das Cidades. Secretaria Nacional de Saneamento Ambiental - SNSA. Sistema Nacional de Informações sobre Saneamento: Diagnóstico dos Serviços de Água e Esgotos - 2015. Brasília: SNSA/MCIDADES, 2017

CASTRO, C. N. de. Transposição do rio São Francisco: análise de oportunidade do projeto. 1577 Texto para discussão. Rio de janeiro: IPEA, 2011. 
CASTRO, J. E. Políticas públicas de saneamento e condicionantes sistêmico. In: CASTRO, J. E. e HELLER, L. Política pública e gestão de serviços de saneamento. Belo Horizonte: Editora UFMG; Rio de Janeiro: Editora Fiocruz, 2013.

DRYZEK, John S. The politics of the earth: environment discourses. Oxford: Oxford University Press, 1997.

FERRY, L. A nova ordem ecológica. Rio de Janeiro, Difel, 2009.

FURTADO, C. Em busca de novo modelo: reflexões sobre a crise contemporânea. São Paulo: Paz e Terra, 2002.

GEHARDT, C. H., ALMEIDA, J. A dialética dos campos sociais na interpretação da problemática ambiental: uma análise crítica a partir de diferentes leituras sobre os problemas ambientais. Ambiente \& Sociedade - Vol. VIII no. 2 jul./dez, 2005.

GEHARDT, C. H. Pesquisadores, populações e áreas protegidas. Tese de Doutorado, Programa de Pós-Graduação de Ciências Sociais em Desenvolvimento, Agricultura e Sociedade, Universidade Federal Rural do Rio de Janeiro, Rio de Janeiro, 2008.

GIDDENS, Anthony. As conseqüências da modernidade. São Paulo: Editora da UNESP, 1991.

JACOBI, P. R. Planejamento e participação na governança da água no Brasil e suas interfaces com a governabilidade dos serviços de saneamento. In: CASTRO, J. E. e HELLER, L. Política pública e gestão de serviços de saneamento. Belo Horizonte: Editora UFMG; Rio de Janeiro: Editora Fiocruz, 2013.

HENKES, S. L. A política, o direito e o desenvolvimento: um estudo sobre a transposição do rio São Francisco. Revista Direito GV, v. 10, n. 2, p. 497-534, São Paulo, Jul./dez. 2014.

IBGE. Estimativas da população residente nos municípios e para as unidades da federação brasileiros com data de referência em 10 de julho de 2016: [notas metodológicas]. Rio de Janeiro: IBGE, 2016.

LEFF, E. Saber ambiental: sustentabilidade, racionalidade, complexidade, poder. Petrópolis, RJ: Vozes, 2001.

Epistemologia ambiental. 5. ed. São Paulo: Cortez, 2002.

LIMA, M. H. C. C. de A. Transposição do São Francisco: conflitos e articulações. Encontro Anual da Anpocs, GT4, conflitos ambientais, processos de territorialização e identidades sociais, 2009.

LIMA, T. V. P. C. Os impactos da transposição do rio São Francisco na sua região de influência. 2013. 100 f. Trabalho de Conclusão de Curso. (Bacharel em Geografia) - Universidade de Brasília, Brasília. 2013.

LOPES, S. L. L. "Sobre processos de "ambientalização" dos conflitos e sobre dilemas da participação", Revista Horizontes Antropológicos, Porto Alegre, ano 12, n. 25, 31-64, jan/jun, 2006. 
LOPES, S. L. L. Sobre processos de ambientalização dos conflitos e sobre dilemas da participação. Horizontes Antropológicos, Porto Alegre, ano 12, n. 25, p. 31-64, jan./jun. 2006.

LOPES, S. L. L. (Coord.) e ANTONAZ, D, PRADO, R., SILVA, Gláucia (Orgs.). A ambientalização dos conflitos sociais: participação e controle público da poluição industrial. Rio de Janeiro: RemumeDumará, 2004.

MACHADO, C. J. S. et al. Promoção da relação saúde - saneamento -cidade por meio da Virologia Ambiental. In: Revista de Informação Legislativa, Ano 50 Número 199 jul./set. 2013.

MALVEZZI, R. Semi-árido uma visão holística. Brasília: CONFEA, 2007.

MINISTÉRIO PÚBLICO FEDERAL. INQUÉRITO CIVIL No 1.24.004.000005/2017-61. Acessado em 2 de fevereiro de 2017, disponível em http://www.mpf.mp.br/pb/sala-deimprensa/docs/recomendacao-transposicao-eixo-leste-meta-3l/view.

MOL, A. P. J. e SPAARGAREN, G. Sociologia, Meio Ambiente e Modernidade - Modernização Ecológica: uma teoria de mudança social. Ihéus: editora da UESC, 1995.

OLIVEIRA, L. M. O princípio da participação ambiental no processo de transposição do rio São Francisco. 2007. 134 f. Dissertação (Mestrado em Direito) - Pontifícia Universidade Católica de Minas Gerais, Belo Horizonte.

ONU. Transforming our world: the 2030 Agenda for Sustainable DevelopmentResolution adopted by the General Assembly on 25 September 2015. Acesso, em 14 de abril de 2017, disponível em: http://www.un.org/ga/search/view_doc.asp?symbol=A/RES/70/1\&Lang=E.

PAGANO, L. M. P. Políticas públicas de poverty alleviation e a transposição dorio são francisco: A Quem Serve a Transposição do Rio São Francisco? Dissertação de Mestrado, Mestrado Profissional em Gestão de Políticas Públicas e Segurança Social, Universidade Federal do Recôncavo da Bahia, Cruz das Almas.(BRASIL, 2004, 2006, 2009. COELHO et al, 2007), 2012.

PSIRU, Food \& Water Watch, Corporate Accountability International, Remunicipalisation Tracker. Veio para ficar: a remunicipalização da água como uma tendência global. In Uni- dade Internacional de Pesquisa de Serviços Públicos Editado por: Madeleine Bélanger Dumontier (PSIRU), Instituto Transnacional (TNI) e Observatório Multinacional, 2015. Disponível em: https://www.tni.org/files/download/heretostay-pt.pdf, acessado em 20 de Janeiro de 2017.

ROCHA, J. M. da. Sustentabilidade em questão: economia, sociedade e meio ambiente, Jundiaí, Paco editorial, 2011.

RODRIGUES, A. M. Estatuto da Cidade: função social da cidade e da propriedade. Alguns aspectos sobre população urbana e espaço. In n. Cadernos Metrópoles: desigualdade e governança, 12 (2004).

SACHS, I. Desenvolvimento: includente, sustentável, sustentado. Rio de Janeiro: Garamond, 2008.(SILVA e OLIVEIRA, 2016) 
SARMENTO, F. J. "A integração do São Francisco: verdade e mito". Revista USP, no70 jun/ago, 2006.

SEN, A. K. Desenvolvimento como liberdade. São Paulo: Companhia das Letras, 2000.

SILVA, J. I. A. O. Ressignificação Ambiental e modernização ecológica no Semiárido: o projeto de integração e revitalização do São Francisco. 1. ed. São Paulo: Hucitec, 2016.

"A institucionalização da questão ambiental no Brasil: modernização ecológica e gestão racional de recursos nos projetos de transposição e revitalização do rio São Francisco", Programa de Pós-graduação em Ciências Sociais, Universidade Federal de Campina Grande, Campina Grande, 2014.

A dimensão ambiental como política pública e condicionante para o desenvolvimento. In: MELO, Clóvis Alberto Vieira de; SOARES, Kelly Cristina Costa. Instituições, gestão pública e desenvolvimento: perfil socioeconômico e político do Cariri Paraibano. Recife: Editora Nossa Livraria, 2011. p. 247-288.

SILVA, J. I. A. O. e CRUZ, V. de A. Gestão dos resíduos sólidos no município de serra Branca-PB: uma análise a partir da política nacional de resíduos sólidos. In: SILVA, J. I. A. O. e MEDEIROS JÚNIOR, G. Programa de Educação Tutorial e as multifaces da gestão contemporânea. Campina Grande: EDUEPB, 2015.

SILVA, J. I. A. O. e OLIVEIRA, J. B. de S. A. de. Água, meio ambiente e desenvolvimento: "Ecologização" de projetos hídricos. In: Raízes, v.36, n.1, jan-jun /2016.

SILVA, J. I. A. O.; CUNHA, L. H. Desenvolvimento e sustentabilidade nos projetos de transposição e revitalização do Rio São Francisco: a institucionalização da questão ambiental via modernização ecológica. Revista Política e Planejamento Regional. Rio de Janeiro, v. 1, n. 2, p. 157 a 176. jul./dez. 2014.

SWYNGEDOUW, E. Águas revoltas: a economia política dos serviços públicos essenciais. In: CASTRO, J. E. e HELLER, L. Política pública e gestão de serviços de saneamento. Belo Horizonte: Editora UFMG; Rio de Janeiro: Editora Fiocruz, 2013.

WORLD WILDLIFE FUND (WWF). Pipedrams? In- terbasin water transfers and water shortages, 2007, disponível em http://www.wwf.or.jp/activities/lib/pdf/pipedreams_27_june_2007_1. pdf, acesso em 1 de dezembro de 2012, às 15 horas.

WORLD BANK. World Development Report. Governante e Law. Washington: World Bank Publications, 2017.

Trabalho enviado em 04 de abril de 2017.

Aceito em 12 de junho de 2017. 